\title{
Polycyclotrimerization of Aromatic Diynes: Synthesis, Thermal Stability, and Light-Emitting Properties of Hyperbranched Polyarylenes
}

\author{
MATTHIAS HÄUßLER, ${ }^{1}$ JIANZHAO LIU, ${ }^{1}$ JACKY WING YIP LAM, ${ }^{1}$ ANJUN QIN, ${ }^{1,2}$ RONGHUA ZHENG, ${ }^{1}$ \\ BEN ZHONG TANG ${ }^{1,2}$ \\ ${ }^{1}$ Department of Chemistry, The Hong Kong University of Science and Technology, Clear Water Bay, Kowloon, \\ Hong Kong, China \\ ${ }^{2}$ Department of Polymer Science and Engineering, Zhejiang University, Hangzhou 310027, China
}

Received 3 April 2007; accepted 2 June 2007

DOI: 10.1002 / pola.22246

Published online in Wiley InterScience (www.interscience.wiley.com).

\begin{abstract}
New aromatic diyne monomers of 1,4-diethynyl-2,5-(dihexyloxy)benzene (1), 1,6-diethynyl-2-(hexyloxy)naphthalene (2), and 9,9-bis(4-ethynylphenyl)fluorene (3) are synthesized. Their homopolymerizations and copolymerizations with 1-octyne (4) or phenylacetylene (5) are effected by $\mathrm{TaBr}_{5}-\mathrm{Ph}_{4} \mathrm{Sn}$ and $\mathrm{CpCo}(\mathrm{CO})_{2}-h v$, giving soluble hyperbranched polyarylenes with high molecular weights $\left(M_{\mathrm{w}}\right.$ up to $\sim 2.9 \times$ $10^{5}$ ) in high yields (up to 99\%). The structures and properties of the polymers are characterized and evaluated by IR, NMR, UV, PL, and TGA analysis. The polymers show excellent thermal stability $\left(T_{\mathrm{d}}>400{ }^{\circ} \mathrm{C}\right)$ and carbonize when pyrolyzed at $900{ }^{\circ} \mathrm{C}$. Upon photoexcitation, the polymers emit deep blue light in the vicinity of $\sim 400 \mathrm{~nm}$ with fluorescence quantum yields up to $92 \%$. ( ) 2007 Wiley Periodicals, Inc. J Polym Sci Part A: Polym Chem 45: 4249-4263, 2007
\end{abstract}

Keywords: alkynes; copolymerization; hyperbranched; light-emitting polymers; polyaromatic; polycyclotrimerization

\section{INTRODUCTION}

During the search for new materials, researchers have been attracted by the molecules with dendritic structures. ${ }^{1,2}$ The unique spherical shapes of the molecules combined with high surface functionalities make them promising for many potential applications. ${ }^{3-8}$ Whereas perfect dendrimers with regular branches are prepared by tedious stepwise synthetic procedures, their imperfect analogs, hyperbranched polymers, are accessible through simple one-step polymerization protocols. ${ }^{9-13}$

Correspondence to: B. Z. Tang (E-mail: tangbenz@ust.hk) Journal of Polymer Science: Part A: Polymer Chemistry, Vol. 45, 4249-4263 (2007) ○2 2007 Wiley Periodicals, Inc.
Despite intensive research efforts, methodologies for the synthesis of hyperbranched polymers have been limited to self-condensations of $\mathrm{AB}_{2}$ monomers, where $\mathrm{A}$ and $\mathrm{B}$ are mutually reactive functional groups with chemical or physical bond-forming capabilities. Due to the involved difficulty in preparing the building blocks with two kinds of mutually reactive functional groups, other approaches such as copolycondensations of $\mathrm{A}_{2}$ and $\mathrm{B}_{3}$ monomers, ${ }^{14}$ self-condensing vinyl polymerizations, ${ }^{15}$ and ring-opening and proton transfer protocols ${ }^{16}$ have been proposed.

Among the different methods developed, polycycloaddition has been proven to be highly effective for the construction of hyperbranched polymers. Hyperbranched polyphenylenes with high 
molecular weights, for example, could be prepared from alkynyl-substituted tetraphenylcyclopentadienones via Diels-Alder reaction. ${ }^{17}$ Recently, click polymerization or 1,3-dipolar polycycloaddition of acetylenes with azides has been utilized to synthesize regiorandom or stereoregular hyperbranched polytriazoles. ${ }^{18,19}$

All the methods described earlier involve the reactions between two different functional groups. The stoichiometric requirements between the pairs of the functional comonomers are, however, practically difficult to meet, which often limits the growth of propagating species, resulting in the formation of oligomeric products. Our research group has worked on the synthesis of hyperbranched polymers via $[2+2+$ 2] polycyclotrimerization of diynes. ${ }^{20,21}$ This polycycloaddition reaction involves a single monomer species, suffers no stoichiometric constraints, and can thus potentially produce polymers with very high molecular weights. Through systematic investigations, we have developed effective catalyst systems and have optimized the reaction conditions for the synthesis of a wide variety of hyperbranched poly(alkylenephenylene)s, polyarylenes, and poly(aroylarylenes). The homopolycyclotrimerizations of diynes as well as their copolycyclotrimerizations with monoynes have furnished a broad range of hyperbranched polymers, which are soluble in common organic solvents, thermally very stable ( $T_{\mathrm{d}}$ up to $\sim 500{ }^{\circ} \mathrm{C}$ ), highly photoluminescent (quantum yields up to 98\%), and strongly attenuate intense laser pulses. In this work, we extended our research efforts in the area. We synthesized new hyperbranched polyarylenes
( $h b$-PAs) containing chromophoric moieties (Scheme 1) and investigated their thermal and optical properties.

\section{EXPERIMENTAL}

\section{Materials and Instrumentations}

Unless otherwise stated, all the reagents and solvents used in this study were purchased from Aldrich and used as received without further purification. Toluene, hexane, and tetrahydrofuran (THF) were distilled from sodium benzophenone ketyl immediately prior to use. Dichloromethane (DCM) was distilled over calcium hydride. Triethylamine was distilled under nitrogen and stored in a dark, cold place over sodium hydroxide. 1,4-Diethynyl-2,5-bis(hexyloxy) benzene (1) was prepared according to published methods. $^{22}$ 1-Octyne and phenylacetylene were purchased from Farchan, stored in a dark, cold and dry place, and distilled over calcium hydride before use.

Weight- $\left(M_{\mathrm{w}}\right)$ and number-average molecular weights $\left(M_{\mathrm{n}}\right)$ and polydispersity indices (PDI; $M_{\mathrm{w}} / M_{\mathrm{n}}$ ) of the polymers were estimated by a Waters Associates gel permeation chromatograph (GPC) system in THF using a set of monodisperse linear polystyrenes as calibration standards. IR spectra were recorded on a Perkin-Elmer 16 PC FTIR spectrophotometer using pressed $\mathrm{KBr}$ plates. ${ }^{1} \mathrm{H}$ and ${ }^{13} \mathrm{C}$ NMR spectra were measured on a Bruker ARX 300 NMR spectrometer using chloroform- $d$ or DCM- $d_{2}$ as solvent and tetramethylsilane (TMS) as internal

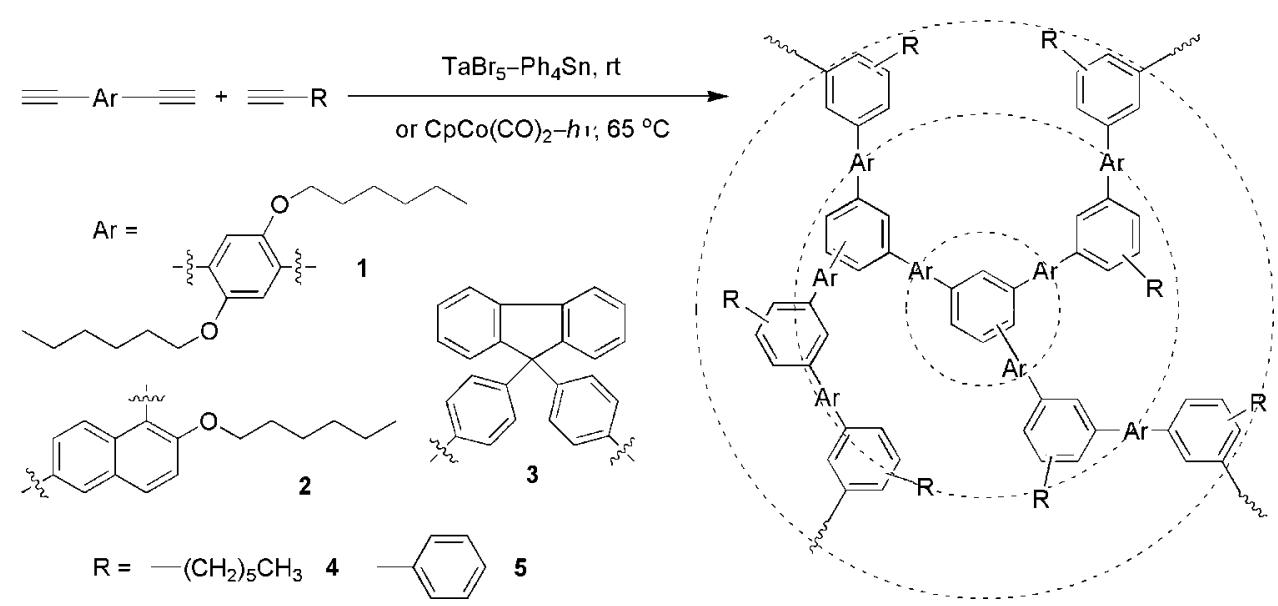

Scheme 1. Synthesis of hyperbranched polyarylenes ( $h b$-PAs) by copolycyclotrimerization of diynes (1-3) and monoynes (4 and 5). 
reference. Elemental analysis was performed on a ThermoFinnigan Flash EA 1112 analyzer. UV absorption spectra were measured on a Milton Ray Spectronic 3000 Array spectrophotometer. Fluorescence spectra of the polymer solutions were recorded in DCM on an SLM 8000C spectrofluorometer. Thermogravimetric analyses (TGA) of the polymers were carried out on a PerkinElmer TGA 7 analyzer at a heating rate of $20^{\circ} \mathrm{C} /$ min under nitrogen.

\section{Synthesis of Monomers}

\section{1,6-Dibromo-2-(hexyloxy)naphthalene (7)}

In a $250-\mathrm{mL}$ three-necked flask equipped with a condenser, a nitrogen inlet and a septum were placed $4 \mathrm{~g}$ (13.2 mmol) of 1,6-dibromonaphthalen-2-ol (6) and $2.1 \mathrm{~mL}(15 \mathrm{mmol})$ of 1-bromohexane in $100 \mathrm{~mL}$ of acetone/DMSO mixture $(9: 1, \mathrm{v} / \mathrm{v})$. To this mixture were added $0.84 \mathrm{~g}$ (15 $\mathrm{mmol})$ of $\mathrm{KOH}$ and $0.3 \mathrm{~g}$ ( $2 \mathrm{mmol})$ of $\mathrm{KI}$, and the resultant mixture was refluxed for $12 \mathrm{~h}$. Acetone was evaporated at reduced pressure. After the addition of water, the residue was extracted with chloroform for three times. The organic layer was further washed three times with water and brine and was then dried over anhydrous $\mathrm{MgSO}_{4}$. After solvent evaporation, a pale yellow crude product was obtained, which was purified by silica-gel column chromatography using chloroform as eluent. A white solid was obtained in $88.6 \%$ yield $(4.5 \mathrm{~g})$.

${ }^{1} \mathrm{H}$ NMR $\left(300 \mathrm{MHz}, \mathrm{CDCl}_{3}\right), \delta$ (TMS, ppm): 8.08 [d, $1 \mathrm{H}$, Naphthalene (Nap) $-\mathrm{H}$ at 8 position], $7.92(\mathrm{~s}, 1 \mathrm{H}, \mathrm{Nap}-\mathrm{H}$ at 5 position), 7.68 (d, $1 \mathrm{H}, \mathrm{Nap}-\mathrm{H}$ at 7 position), $7.59(\mathrm{~d}, 1 \mathrm{H}, \mathrm{Nap}-\mathrm{H}$ at 4 position), $7.24(\mathrm{~d}, 1 \mathrm{H}, \mathrm{Nap}-\mathrm{H}$ at 3 position), $4.16\left(\mathrm{t}, 2 \mathrm{H}, \mathrm{O}-\mathrm{CH}_{2}\right), 1.87(\mathrm{dd}, 2 \mathrm{H}$, $\left.\mathrm{OCH}_{2} \mathrm{CH}_{2}\right), 1.54\left(\mathrm{~m}, 2 \mathrm{H}, \mathrm{CH}_{2}\right), 1.36(\mathrm{~m}, 4 \mathrm{H}$, $\left.\mathrm{CH}_{2}\right), 0.91\left(\mathrm{t}, 3 \mathrm{H}, \mathrm{CH}_{3}\right.$ ).

\section{2-Hexyloxy-1,6-diiodonaphthalene (8)}

In a 100-mL two-necked, round-bottom flask equipped with a condenser, a nitrogen inlet, and a stirrer bar were dissolved $4.5 \mathrm{~g}(11.7 \mathrm{mmol})$ of 7, $2.3 \mathrm{~g}$ (11.7 mmol) of copper iodine, $5.8 \mathrm{~g}$ (35.1 $\mathrm{mmol}$ ) of $\mathrm{KI}$ in $50 \mathrm{~mL}$ of hexamethylphosphoramide. The mixture was heated at $150{ }^{\circ} \mathrm{C}$ for $24 \mathrm{~h}$ on a sand-bath. After completion of the reaction, the mixture was poured into $200 \mathrm{~mL}$ of water and extracted with $50 \mathrm{~mL}$ of chloroform for three times. The combined organic phases were washed with water, sodium thiosulfate solution (1 M), and brine, and then dried over anhydrous magnesium sulfate. Evaporation of the organic solvent gave a yellow, viscous oil in $78.3 \%$ yield $(4.4 \mathrm{~g})$, which was directly used in the next reaction without further purification.

\section{2-Hexyloxy-1,6-bis[2-(trimethylsilyl)ethynyl] naphthalene (9)}

To a 500-mL round-bottom flask equipped with a septum and a stirring bar was added $4.4 \mathrm{~g}$ $(9.2 \mathrm{mmol})$ of $8,77.1 \mathrm{mg}(0.11 \mathrm{mmol})$ of $\mathrm{Pd}$ $\left(\mathrm{PPh}_{3}\right)_{2} \mathrm{Cl}_{2}, 38 \mathrm{mg}(0.2 \mathrm{mmol})$ of $\mathrm{CuI}$, and $52 \mathrm{mg}$ $(0.2 \mathrm{mmol})$ of $\mathrm{PPh}_{3}$ under nitrogen in a glovebox. Dry triethylamine $(100 \mathrm{~mL})$ and THF $(100 \mathrm{~mL})$ were then injected by a syringe. Afterwards, $2.9 \mathrm{~mL}(20.4 \mathrm{mmol})$ of (trimethylsilyl)acetylene (TMSA) was added under stirring. The mixture was kept stirring at room temperature for $12 \mathrm{~h}$. The formed precipitate was filtered and washed with diethyl ether. The solutions were collected and the solvent was removed under reduced pressure. A white solid was obtained after purification by silica-gel column chromatography using hexane/chloroform $(3: 1, \mathrm{v} / \mathrm{v})$ as eluent in $87.9 \%$ yield $(3.4 \mathrm{~g})$.

${ }^{1} \mathrm{H}$ NMR (300 $\mathrm{MHz}, \mathrm{CDCl}_{3}$ ), $\delta$ (TMS, ppm): $8.12(\mathrm{~d}, 1 \mathrm{H}, \mathrm{Nap}-\mathrm{H}$ at 8 position $), 7.89(\mathrm{~s}, 1 \mathrm{H}$, $\mathrm{Nap}-\mathrm{H}$ at 5 position), $7.68(\mathrm{~d}, 1 \mathrm{H}, \mathrm{Nap}-\mathrm{H}$ at 7 position), 7.51 (d, 1H, Nap-H at 4 position), $7.17(\mathrm{~d}, 1 \mathrm{H}, \mathrm{Nap}-\mathrm{H}$ at 3 position), $4.16(\mathrm{t}, 2 \mathrm{H}$, $\left.\mathrm{O}-\mathrm{CH}_{2}\right), 1.86\left(\mathrm{dd}, 2 \mathrm{H}, \mathrm{OCH}_{2} \mathrm{CH}_{2}\right), 1.57(\mathrm{~m}, 2 \mathrm{H}$, $\left.\mathrm{CH}_{2}\right), 1.37\left(\mathrm{~m}, 4 \mathrm{H}, \mathrm{CH}_{2}\right), 0.92\left(\mathrm{t}, 3 \mathrm{H}, \mathrm{CH}_{3}\right), 0.33$ $\left(\mathrm{s}, 9 \mathrm{H}, \mathrm{Si}-\mathrm{CH}_{3}\right.$ at position 6$), 0.28(\mathrm{~s}, 9 \mathrm{H}$, $\mathrm{Si}-\mathrm{CH}_{3}$ at position 1).

\section{1,6-Diethynyl-2-(hexyloxy)naphthalene (2)}

To a 250-mL round-bottom flask equipped with a stirring bar was added $3.4 \mathrm{~g}(8.1 \mathrm{mmol})$ of $\mathbf{9}$, $100 \mathrm{~mL}$ of methanol, $50 \mathrm{~mL}$ of THF, and $1.1 \mathrm{~g}$ $(19.6 \mathrm{mmol})$ of $\mathrm{KOH}$. After stirring at room temperature for $3 \mathrm{~h}$, the solution was concentrated and poured into $500 \mathrm{~mL}$ of $1 \mathrm{M} \mathrm{HCl}$ solution. The mixture was extracted with chloroform for four times. The organic layer was collected, dried over magnesium sulfate, and concentrated by a rotary evaporator. The obtained product was purified by silica-gel column chromatography using hexane/chloroform (3:1, v/v) as eluent to give a white solid in $96.9 \%$ yield $(2.2 \mathrm{~g})$.

IR $(\mathrm{KBr}), v\left(\mathrm{~cm}^{-1}\right): 3269$ ( $\equiv \mathrm{C}-\mathrm{H}$ stretching), 3070 (Ar-H stretching), 2954, 2919, 2872, 2852 
(aliphatic $\mathrm{C}-\mathrm{H}$ stretching), $2092(\mathrm{C} \equiv \mathrm{C}$ stretching), 1620, 1587, 1495, $1465(\mathrm{C}=\mathrm{C}$ ring stretching), 1337, $1270(\mathrm{C}-\mathrm{H}$ bending) 1249, 1080, (C-O stretching) $1030,664\left(\mathrm{C}-\mathrm{H}\right.$ rocking). ${ }^{1} \mathrm{H}$ NMR (300 MHz, $\mathrm{CDCl}_{3}$ ), $\delta$ (TMS, ppm): 8.19 (d, $1 \mathrm{H}, \mathrm{Nap}-\mathrm{H}$ at 8 position), 7.95 (s, $1 \mathrm{H}, \mathrm{Nap}-\mathrm{H}$ at 5 position), $7.76(\mathrm{~d}, 1 \mathrm{H}, \mathrm{Nap}-\mathrm{H}$ at 7 position), $7.57(\mathrm{~d}, 1 \mathrm{H}, \mathrm{Nap}-\mathrm{H}$ at 4 position), 7.24 (d, $1 \mathrm{H}, \mathrm{Nap}-\mathrm{H}$ at 3 position), $4.21(\mathrm{t}, 2 \mathrm{H}$, $\left.\mathrm{O}-\mathrm{CH}_{2}\right), 3.69(\mathrm{~s}, 1 \mathrm{H}, \equiv \mathrm{C}-\mathrm{H}$ at 6 position), $3.12(\mathrm{~s}, 1 \mathrm{H}, \equiv \mathrm{C}-\mathrm{H}$ at 1 position $), 1.88(\mathrm{dd}, 2 \mathrm{H}$, $\left.\mathrm{OCH}_{2} \mathrm{CH}_{2}\right), 1.54\left(\mathrm{~m}, 2 \mathrm{H}, \mathrm{CH}_{2}\right), 1.37(\mathrm{~m}, 4 \mathrm{H}$, $\left.\mathrm{CH}_{2}\right), 0.91\left(\mathrm{t}, 3 \mathrm{H}, \mathrm{CH}_{3}\right) .{ }^{13} \mathrm{C}$ NMR $(75 \mathrm{MHz}$, $\mathrm{CDCl}_{3}$ ), $\delta$ (ppm): 160.07, 134.55, 132.27, 130.19, $129.98,127.62,125.25,117.56,114.55,105.71$, 86.62, 83.84, 77.76, 77.19, 69.67, 31.57, 29.32, 25.62, 22.66, 14.11. AnaL.: Calcd. for $\mathrm{C}_{20} \mathrm{H}_{20} \mathrm{O}: \mathrm{C}$, 86.92; H, 7.29. Found: C, 86.89; H, 7.34.

\section{9,9-Bis(4-iodophenyl)fluorene (11)}

In a $250-\mathrm{mL}$ round-bottom flask equipped with a condenser and a magnetic stirrer bar was dissolved $2 \mathrm{~g}$ ( $5.7 \mathrm{mmol})$ of $\mathbf{1 0}$ in a mixture of $7 \mathrm{~mL}$ of concentrated hydrochloric acid, $70 \mathrm{~mL}$ of water, and $20 \mathrm{~mL}$ of THF. The flask was cooled in an ice-bath. To this mixture was slowly added $0.83 \mathrm{~g}(12 \mathrm{mmol})$ of sodium nitrite dissolved in $25 \mathrm{~mL}$ of water while maintaining the temperature below $5{ }^{\circ} \mathrm{C}$. The reaction mixture was stirred for $10 \mathrm{~min}$ at $0{ }^{\circ} \mathrm{C}$, after which $2.3 \mathrm{~g}$ (14 mmol) of KI dissolved in $40 \mathrm{~mL}$ of water was added dropwise. After the addition, the mixture was refluxed for $15 \mathrm{~min}$, cooled, and stirred at room temperature overnight. The reaction mixture was poured into $200 \mathrm{~mL}$ of water and extracted with $50 \mathrm{~mL}$ of chloroform for three times. The organic phases were combined and washed with water, sodium thiosulfate solution $(1 \mathrm{M})$, and brine, and then dried over anhydrous magnesium sulfate. A white solid was obtained after purification by silica-gel column chromatography using chloroform as eluent in $85.6 \%$ yield $(2.8 \mathrm{~g})$.

${ }^{1} \mathrm{H}$ NMR (300 $\mathrm{MHz}, \mathrm{CDCl}_{3}$ ), $\delta$ (TMS, ppm): $7.79(\mathrm{~d}, 2 \mathrm{H}$, Fluorene $(\mathrm{Flu})-\mathrm{H}$ at 4 and 5 positions), $7.55(\mathrm{~m}, 4 \mathrm{H}, \mathrm{Ar}-\mathrm{H}$ at 3 and 5 positions $)$, $7.33(\mathrm{~m}, 6 \mathrm{H}, \mathrm{Flu}-\mathrm{H}), 6.92(\mathrm{~d}, 4 \mathrm{H}, \mathrm{Ar}-\mathrm{H}$ at 2 and 6 positions).

\section{9,9-Bis\{4-[2-(trimethylsilyl)ethynyl]phenyl\}fluorene (12)}

This compound was prepared by the procedures similar to those for the preparation of $\mathbf{9}$, using
$2.7 \mathrm{~g}(4.7 \mathrm{mmol})$ of 14 and $1.5 \mathrm{~mL}(10.3 \mathrm{mmol})$ of TMSA as starting materials. A white solid was obtained from a silica-gel column using hexane/chloroform $(4: 1, \mathrm{v} / \mathrm{v})$ as eluent in $91.5 \%$ yield $(2.2 \mathrm{~g})$.

${ }^{1} \mathrm{H}$ NMR (300 $\mathrm{MHz}, \mathrm{CDCl}_{3}$ ), $\delta$ (TMS, ppm): $7.77(\mathrm{~d}, 2 \mathrm{H}, \mathrm{Flu}-\mathrm{H}$ at 4 and 5 positions), 7.33 (m, 10H, Flu $-\mathrm{H}$ and $\mathrm{Ar}-\mathrm{H}$ at 3 and 5 positions), 7.08 (d, $4 \mathrm{H}, \mathrm{Ar}-\mathrm{H}$ at 2 and 6 positions), $0.22\left(\mathrm{~s}, 18 \mathrm{H}, \mathrm{Si}-\mathrm{CH}_{3}\right)$.

\section{9,9-Bis(4-ethynylphenyl)fluorene (3)}

This monomer was prepared by the procedures similar to those for the synthesis of 2, using $2.2 \mathrm{~g}(4.3 \mathrm{mmol})$ of 12 and $0.5 \mathrm{~g}(8.9 \mathrm{mmol})$ of $\mathrm{KOH}$ as reactants. A white solid was obtained after purification by silica-gel column chromatography using hexane/chloroform $(2: 1, \mathrm{v} / \mathrm{v})$ as eluent in $94.7 \%$ yield $(1.5 \mathrm{~g})$.

IR $(\mathrm{KBr}), v\left(\mathrm{~cm}^{-1}\right): 3282(\equiv \mathrm{C}-\mathrm{H}$ stretching $)$, 3058, $3033 \quad(\mathrm{Ar}-\mathrm{H} \quad$ stretching $), 2107 \quad(\mathrm{C} \equiv \mathrm{C}$ stretching $), 1600,1499,1447(\mathrm{C}=\mathrm{C}$ ring stretching). ${ }^{1} \mathrm{H}$ NMR (300 MHz, $\mathrm{CDCl}_{3}$ ), $\delta$ (TMS, ppm): $7.74(\mathrm{~d}, 2 \mathrm{H}, \mathrm{Flu}-\mathrm{H}$ at 4 and 5 position), 7.32 $(\mathrm{m}, 10 \mathrm{H}, \mathrm{Flu}-\mathrm{H}$ and $\mathrm{Ar}-\mathrm{H}$ at 3 and 5 position), $7.13(\mathrm{~d}, 4 \mathrm{H}, \mathrm{Ar}-\mathrm{H}$ at 2 and 6 position), $3.01(\mathrm{~s}, 2 \mathrm{H}, \equiv \mathrm{C}-\mathrm{H}) .{ }^{13} \mathrm{C} \quad \mathrm{NMR} \quad(75 \mathrm{MHz}$, $\mathrm{CD}_{2} \mathrm{Cl}_{2}$ ), $\delta$ (ppm): 150.12, 146.31, 140.10, 132.10, $132.01,128.01,127.91,125.96,120.34,128.29$, 83.35, 77.44, 65.23. ANAL.: Calcd for $\mathrm{C}_{29} \mathrm{H}_{18}$ : C, 95.05; H, 4.95. Found: C, 95.01; H, 4.98 .

\section{Polymerization}

All the polymerization reactions and manipulations were carried out under nitrogen using standard Schlenk techniques in a vacuum line system or an inert-atmosphere glovebox, except for the purification of the polymers, which was done in an open atmosphere. A typical experimental procedure for the copolymerization of $\mathbf{1}$ and $\mathbf{5}$ is given below as an example.

To a thoroughly baked and carefully evacuated 15-mL Schlenk tube with a stopcock on the sidearm were placed $29 \mathrm{mg}(0.05 \mathrm{mmol})$ of $\mathrm{TaBr}_{5}$ and $22 \mathrm{mg}(0.05 \mathrm{mmol})$ of $\mathrm{Ph}_{4} \mathrm{Sn}$ under nitrogen in a glovebox. Freshly distilled toluene $(3 \mathrm{~mL})$ was injected into the tube and the mixture was stirred for $10 \mathrm{~min}$. Diyne $1(117.5 \mathrm{mg}$, $0.36 \mathrm{mmol})$ and monoyne $\mathbf{5}(74.2 \mathrm{mg}, 0.72 \mathrm{mmol})$ dissolved in $2 \mathrm{~mL}$ of dry toluene were then injected into the catalyst solution. The resulting 
Table 1. Synthesis of Hyperbranched Polyarylenes ${ }^{a}$

\begin{tabular}{ccccccc} 
Run & $h b$-PA & Catalyst & Yield (\%) & $\mathrm{S}^{\mathrm{b}}$ & $M_{\mathrm{w}}{ }^{\mathrm{c}}$ & $M_{\mathrm{w}} / M_{\mathrm{n}}{ }^{\mathrm{c}}$ \\
\hline 1 & P1 & Co & Trace & & & \\
2 & P1 & Ta & 77 & $\mathrm{X}$ & & \\
3 & P2 & Co & 70 & O & 8500 & 2.1 \\
4 & P2 & Ta & Trace & & & \\
5 & P3 & Co & 99 & $\Delta$ & & \\
6 & P3 & Ta & 98 & $\mathrm{X}$ & & \\
\hline
\end{tabular}

a Polymerization reaction carried out under nitrogen in toluene for $12 \mathrm{~h}$ using $\mathrm{CpCo}(\mathrm{CO})_{2}-h v(\mathrm{Co})$ as catalyst at $65{ }^{\circ} \mathrm{C}$ or $\mathrm{TaBr}_{5}-\mathrm{Ph}_{4} \mathrm{Sn}(\mathrm{Ta})$ as catalyst at room temperature. $[$ Diyne $]=72 \mathrm{mM}$. [Catalyst $]=12.5(\mathrm{Co}), 10(\mathrm{Ta}) \mathrm{mM}$.

Solubility (S) tested in common organic solvents such as toluene, THF, dichloromethane, and chloroform; $\mathrm{O}=\mathrm{com}$ pletely soluble; $\Delta=$ partly soluble; $\mathrm{X}=$ insoluble.

${ }^{\mathrm{c}}$ Determined by GPC in THF on the basis of a polystyrene calibration.

mixture was stirred at room temperature under nitrogen for $16 \mathrm{~h}$, after which the reaction was quenched by the addition of methanol. The mixture was added dropwise to $\sim 400 \mathrm{~mL}$ methanol through a cotton filter under stirring. The polymer precipitate was allowed to stand overnight and was then filtered through a Gooch crucible. The isolated polymer was washed with methanol and dried under vacuum at room temperature to a constant weight. White powdery product of $\mathrm{P} \mathbf{1} / \mathbf{5}$ was obtained.

\section{Characterization Data}

P1/5 (Table 2, no. 6): White powder; yield $42.1 \%$. $M_{\mathrm{w}} 7000 ; M_{\mathrm{w}} / M_{\mathrm{n}} 2.5$ (GPC, polystyrene calibration). IR $(\mathrm{KBr}), v\left(\mathrm{~cm}^{-1}\right)$ : $3029(\mathrm{Ar}-\mathrm{H}$ stretching), $2929\left(\mathrm{CH}_{2}\right.$ asymmetrical stretching $), 2858$ $\left(\mathrm{CH}_{2}\right.$ symmetrical stretching), 1596, 1499, 1468 ( $\mathrm{C}=\mathrm{C}$ ring stretching), $1206(\mathrm{C}-\mathrm{H}$ bending $)$, 834, 760, 699 (C-H rocking). ${ }^{1} \mathrm{H}$ NMR (300 $\mathrm{MHz}, \mathrm{CD}_{2} \mathrm{Cl}_{2}$ ), $\delta$ (ppm): 7.85, 7.71, 7.47, 7.39, 7.25, 7.22, 6.95, $6.75(\mathrm{Ar}-\mathrm{H}), 3.99,3.68\left(\mathrm{OCH}_{2}\right)$, $3.36(\equiv \mathrm{C}-\mathrm{H}), 1.71,1.59,1.22,1.16\left(\mathrm{CH}_{2}\right) 0.78$ $\left(\mathrm{CH}_{3}\right) .{ }^{13} \mathrm{C} \mathrm{NMR}\left(75 \mathrm{MHz}, \mathrm{CD}_{2} \mathrm{Cl}_{2}\right), \delta$ (ppm): $150.38,150.05,141.36,140.61,137.22,129.91$, $129.29,128.74,127.82,127.30,126.38,118.98$, $118.67,117.50,116.80,116.19,70.99,31.50$, 29.18, 25.83, 22.49, 14.01 .

P1/4 (Table 2, no. 3): Pale grey powder; yield $75.4 \% . M_{\mathrm{w}} 21,000 ; M_{\mathrm{w}} / M_{\mathrm{n}} 2.1$ (GPC, polystyrene calibration). IR $(\mathrm{KBr}), v\left(\mathrm{~cm}^{-1}\right): 3274(\equiv \mathrm{C}-\mathrm{H}$ stretching), 3028 ( $\mathrm{Ar}-\mathrm{H}$ stretching), 2955, 2925 $\left(\mathrm{CH}_{2}\right.$ asymmetrical stretching), $2855\left(\mathrm{CH}_{2}\right.$ symmetrical stretching), 1596, 1498, $1466 \quad(\mathrm{C}=\mathrm{C}$ ring stretching), 1220, $1198(\mathrm{C}-\mathrm{H}$ bending), 870,659 (C-H rocking). ${ }^{1} \mathrm{H}$ NMR $(300 \mathrm{MHz}$,

Table 2. Synthesis of Hyperbranched Copolyarylenes ${ }^{\text {a }}$

\begin{tabular}{|c|c|c|c|c|c|c|c|}
\hline Run & $h b-\mathrm{PA}$ & $M_{\mathrm{r}}^{\mathrm{b}}$ & Catalyst & Yield $(\%)$ & $\mathrm{S}^{\mathrm{c}}$ & $M_{\mathrm{w}}{ }^{\mathrm{d}}$ & $M_{\mathrm{w}} / M_{\mathrm{n}}^{\mathrm{d}}$ \\
\hline 1 & $\mathrm{P} 1 / 4$ & $1: 1$ & Co & Trace & & & \\
\hline 2 & $\mathrm{P} 1 / 4$ & $1: 1.5$ & $\mathrm{Ta}$ & 71 & $\Delta$ & & \\
\hline 3 & $\mathrm{P} 1 / 4$ & $1: 2$ & $\mathrm{Ta}$ & 75 & $\mathrm{O}$ & 21,000 & 3.1 \\
\hline 4 & $\mathrm{P} 1 / 5$ & $1: 1$ & $\mathrm{Ta}$ & 40 & $\Delta$ & & \\
\hline 5 & $\mathrm{P} \mathbf{1} / \mathbf{5}$ & $1: 1.5$ & $\mathrm{Ta}$ & Trace & & & \\
\hline 6 & $\mathrm{P} 1 / 5$ & $1: 2$ & $\mathrm{Ta}$ & 42 & $\mathrm{O}$ & 7000 & 2.5 \\
\hline 7 & $\mathrm{P} 2 / 4$ & $1: 1$ & Co & Trace & & & \\
\hline 8 & $\mathrm{P} 2 / 4$ & $1: 1.5$ & $\mathrm{Ta}$ & 65 & $\Delta$ & & \\
\hline 9 & $\mathrm{P} 2 / 5$ & $1: 1$ & $\mathrm{Ta}$ & 98 & $\overline{\mathrm{O}}$ & 10,500 & 3.1 \\
\hline 10 & $\mathrm{P3} / 4$ & $1: 1$ & Co & 77 & $\mathrm{O}$ & 7100 & 1.9 \\
\hline 11 & $\mathrm{P} 3 / 4$ & $1: 1$ & $\mathrm{Ta}$ & 99 & $\mathrm{O}$ & 287,400 & 27.8 \\
\hline 12 & $\mathrm{P3} / 4$ & $1: 1.5$ & $\mathrm{Ta}$ & 99 & $\mathrm{O}$ & 28,100 & 5.0 \\
\hline 13 & $\mathrm{P3} / \mathbf{5}$ & $1: 1.5$ & $\mathrm{Ta}$ & 99 & $\Delta$ & & \\
\hline 14 & $\mathrm{P} 3 / \mathbf{5}$ & $1: 2$ & $\mathrm{Ta}$ & 99 & $\mathrm{O}$ & 12,600 & 4.8 \\
\hline
\end{tabular}

\footnotetext{
${ }^{a}$ Polymerization reaction carried out under nitrogen in toluene for $12 \mathrm{~h}$ using $\mathrm{CpCo}(\mathrm{CO})_{2}-h v$ (Co) as catalyst at $65{ }^{\circ} \mathrm{C}$ or $\mathrm{TaBr}_{5}-\mathrm{Ph}_{4} \mathrm{Sn}$ (Ta) as catalyst at room temperature. [Diyne] $=72 \mathrm{mM}$. [Catalyst $]=12.5(\mathrm{Co}), 10(\mathrm{Ta}) \mathrm{mM}$.

${ }^{\mathrm{b}}$ Molar ratio of [diyne]:[monoyne].

${ }^{\mathrm{c}}$ Solubility (S) tested in common organic solvents such as toluene, THF, dichloromethane, and chloroform; $\mathrm{O}=$ completely soluble; $\Delta=$ partly soluble.

${ }^{\mathrm{d}}$ Determined by GPC in THF on the basis of a polystyrene calibration.
} 
$\left.\mathrm{CD}_{2} \mathrm{Cl}_{2}\right), \delta$ (ppm): 7.20, $6.91(\mathrm{Ar}-\mathrm{H}), 3.92\left(\mathrm{OCH}_{2}\right)$, $3.28(\equiv \mathrm{C}-\mathrm{H}), 1.73,1.30\left(\mathrm{CH}_{2}\right) 0.85\left(\mathrm{CH}_{3}\right) \cdot{ }^{13} \mathrm{C}$ NMR (75 MHz, $\mathrm{CD}_{2} \mathrm{Cl}_{2}$ ), $\delta$ (ppm): 150.34, 150.12, $118.98,118.66,117.53,116.78,116.17,70.98$, 34.56, 31.50, 30.28, 29.18, 25.83, 22.48, 14.01 .

P2 (Table 1, no. 3): Pale brown powder; yield $70.0 \% . M_{\mathrm{w}} 8500 ; M_{\mathrm{w}} / M_{\mathrm{n}} 2.1$ (GPC, polystyrene calibration). IR $(\mathrm{KBr}), v\left(\mathrm{~cm}^{-1}\right): 3308(\equiv \mathrm{C}-\mathrm{H}$ stretching), 3065, 3026 (Ar-H stretching), 2953, $2929\left(\mathrm{CH}_{2}\right.$ asymmetrical stretching), 2869 $\left(\mathrm{CH}_{2}\right.$ symmetrical stretching), 2158, $2099(\mathrm{C} \equiv \mathrm{C}$ stretching), 1590, 1491, 1466 ( $\mathrm{C}=\mathrm{C}$ ring stretching), 1275, 1249 (C-H bending), 825, 757 (C-H rocking). ${ }^{1} \mathrm{H}$ NMR (300 $\left.\mathrm{MHz}, \mathrm{CDCl}_{3}\right), \delta$ (ppm): 7.74, 7.41, $7.31(\mathrm{Ar}-\mathrm{H}), 4.15\left(\mathrm{OCH}_{2}\right)$, $3.69(\equiv \mathrm{C}-\mathrm{H}), 1.83,1.33\left(\mathrm{CH}_{2}\right), 0.89\left(\mathrm{CH}_{3}\right)$.

P2/5 (Table 2, no. 9): Pale grey powder; yield 98.1\%. $M_{\mathrm{w}} 10,500 ; M_{\mathrm{w}} / M_{\mathrm{n}} 3.1$ (GPC, polystyrene calibration). IR $(\mathrm{KBr}), \quad v\left(\mathrm{~cm}^{-1}\right): 3053,3027$ (Ar-H stretching), 2950, $2926\left(\mathrm{CH}_{2}\right.$ asymmetrical stretching), $2856\left(\mathrm{CH}_{2}\right.$ symmetrical stretching), 1591, 1466 ( $\mathrm{C}=\mathrm{C}$ ring stretching), 1245 (C-H bending) 825, 760, 698 (C-H rocking). ${ }^{1} \mathrm{H}$ NMR (300 MHz, $\mathrm{CDCl}_{3}$ ), $\delta$ (ppm): 7.86, 7.80, 7.51, 7.21, 7.08 (Nap-H and $\mathrm{Ar}-\mathrm{H}), 4.08$ $\left(\mathrm{OCH}_{2}\right), 1.64,1.20\left(\mathrm{CH}_{2}\right), 0.82\left(\mathrm{CH}_{3}\right) .{ }^{13} \mathrm{C} \mathrm{NMR}$ $\left(75 \mathrm{MHz}, \mathrm{CD}_{2} \mathrm{Cl}_{2}\right), \delta$ (ppm): 153.36, 142.31, $140.52,139.14,137.25,135.34,131.36,129.81$, $128.75,127.77,127.29,125.72,125.12,69.92$, 31.50, 29.51, 25.74, 22.62, 14.12 .

P3/4 (Table 2, no. 12): White powder; yield $99.7 \% . M_{\mathrm{w}} 28,100 ; M_{\mathrm{w}} / M_{\mathrm{n}} 5.0$ (GPC, polystyrene calibration). IR $(\mathrm{KBr}), \quad v\left(\mathrm{~cm}^{-1}\right): 3057,3027$ (Ar-H stretching), 2953, $2926\left(\mathrm{CH}_{2}\right.$ asymmetrical stretching), 2855 ( $\mathrm{CH}_{2}$ symmetrical stretching), 1599, 1507, 1483, $1447(\mathrm{C}=\mathrm{C}$ ring stretching), $1249(\mathrm{C}-\mathrm{H}$ bending) 818, 750, $739(\mathrm{C}-\mathrm{H}$ rocking). ${ }^{1} \mathrm{H} \mathrm{NMR}\left(300 \mathrm{MHz}, \mathrm{CDCl}_{3}\right), \delta$ (ppm): 7.77, 7.44, 7.42, 7.30, 7.25, 7.19, $7.05(\mathrm{Ar}-\mathrm{H})$,
$2.35\left(\mathrm{Ar}-\mathrm{CH}_{2}\right), \quad 1.58,1.29, \quad 1.14\left(\mathrm{CH}_{2}\right), 0.86$ $\left(\mathrm{CH}_{3}\right) .{ }^{13} \mathrm{C} \mathrm{NMR}\left(75 \mathrm{MHz}, \mathrm{CD}_{2} \mathrm{Cl}_{2}\right), \delta$ (ppm): $148.29,141.96,140.14,134.71,133.36,131.87$, $131.44,131.13,129.06,128.46,127.71,127.02$, 126.17, 121.62, 120.17, 66.55, 34.58, 31.41, 30.30, 29.36, 22.57, 14.08.

P3/5 (Table 2, no. 14): White powder; yield $99.9 \% . M_{\mathrm{w}} 12,600 ; M_{\mathrm{w}} / M_{\mathrm{n}} 4.8$ (GPC, polystyrene calibration). IR $(\mathrm{KBr}), v\left(\mathrm{~cm}^{-1}\right): 3054,3027$ $\left(\mathrm{Ar}-\mathrm{H}\right.$ stretching), $2921 \quad\left(\mathrm{CH}_{2}\right.$ asymmetrical stretching), 2851 ( $\mathrm{CH}_{2}$ symmetrical stretching), 1595, 1507, 1474, 1447 ( $\mathrm{C}=\mathrm{C}$ ring stretching), 816, 750, $738\left(\mathrm{C}-\mathrm{H}\right.$ rocking). ${ }^{1} \mathrm{H}$ NMR (300 MHz, $\mathrm{CDCl}_{3}$ ), $\delta$ (ppm): 7.55, 7.49, 7.20, 7.15, 7.07, 6.93, $6.77(\mathrm{Ar}-\mathrm{H}) .{ }^{13} \mathrm{C} \mathrm{NMR}\left(75 \mathrm{MHz}, \mathrm{CD}_{2} \mathrm{Cl}_{2}\right), \delta$ (ppm): 151.01, 140.59, 140.13, 139.38, 139.23, $139.17,129.84,128.78,128.59,128.11,127.82$, $127.71,127.51,127.23,126.52,126.15,125.78$, $124.98,121.23,120.19,117.82,64.98$.

\section{RESULTS AND DISCUSSION}

\section{Monomer Synthesis}

Our group has prepared a large variety of functional aliphatic and aromatic diynes and successfully converted them into hyperbranched conjugated polymers. ${ }^{21}$ To deepen our understanding of this interesting class of materials and enrich our structural library, we designed and prepared three new diyne monomers containing benzene, naphthalene, and fluorene chromophores (1-3), by the synthetic routes shown in Schemes 2 and 3. Diyne $\mathbf{1}$ is known and was prepared according to published methods from hydroquinone by a four-step procedure in $62.5 \%$ overall yield. For diyne 2 , the first step in the preparation is the etherization of the
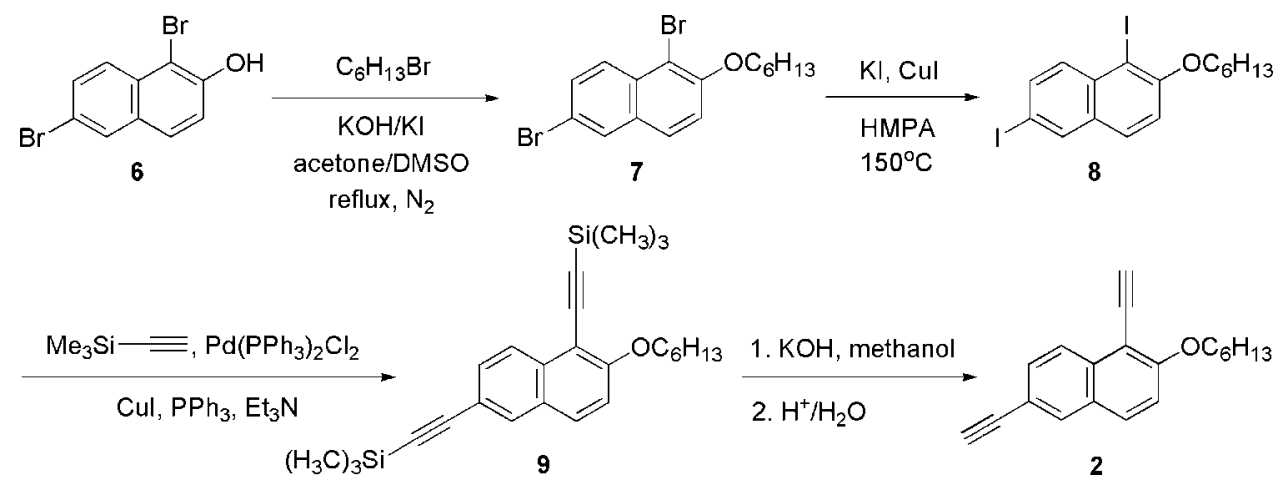

Scheme 2. Synthesis of diyne monomer of 1,6-diethynyl-2-(hexyloxy)naphthalene (2). 

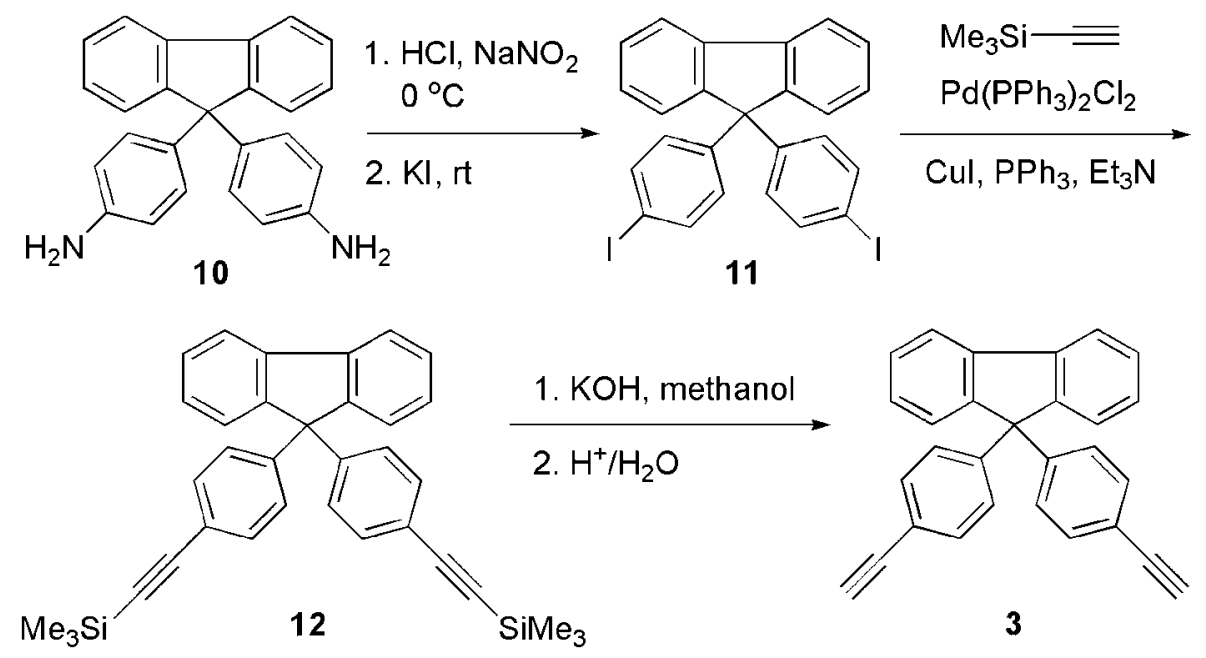

Scheme 3. Synthesis of diyne monomer of 9,9-bis(4-ethynylphenyl)fluorene (3).

hydroxyl group of 6 with 1-bromohexane. Since direct coupling of TMSA with the bromo groups of $\mathbf{7}$ was difficult even at high temperatures and in the presence of excess amounts of TMSA, a CuI-catalyzed halogen exchange (Finkelstein re-

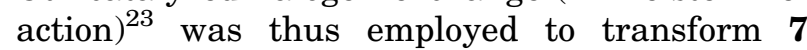
into its diiodide derivative (8). Sonogashira coupling of $\mathbf{8}$ with TMSA followed by base-catalyzed cleavage of the trimethylsilyl groups gave desired diyne 2 in an overall isolated yield of $59.1 \%$.

Diyne 3 was synthesized from its diamine precursor 10. Diazotization and subsequent substitution with iodine furnished diiodide 11, which was converted into 12 by Sonogashiracoupling with TMSA. Cleavage of the trimethylsilyl protection groups under basic conditions finished this three-step reaction protocol of $\mathbf{3}$ in an overall yield of $74.2 \%$.

All the monomers are white powders and have been characterized by spectroscopic methods, from which satisfactory analysis data were obtained (see Experimental section for details).

\section{Polymerization}

We first tried to homopolycyclotrimerize the diynes using $\mathrm{CpCo}(\mathrm{CO})_{2}-h v$ (Co) or $\mathrm{TaBr}_{5}$ $\mathrm{Ph}_{4} \mathrm{Sn}$ (Ta) as catalyst (Table 1 ). While polymerization of 1 initiated by the Co catalyst gave only a trace amount of polymeric product, a polymer was isolated in $77 \%$ yield when the Ta catalyst was used. Unfortunately, however, the polymer was insoluble. Unlike 1, 2 was homopolymerized by the Co catalyst to give a polymer with a moderate molecular weight (8500) and a narrow polydispersity index (2.1) in a high yield $(70 \%)$. The polymer was completely soluble in common organic solvents such as toluene, THF, DCM, and chloroform. Disappointedly, only a trace amount of polymeric product was obtained when the polymerization of $\mathbf{2}$ was conducted in the presence of the Ta catalyst. Different structures of the monomers (benzene in $\mathbf{1}$ vs. naphthalene in $\mathbf{2}$, and two alkoxy groups in $\mathbf{1}$ vs. one in 2) and different activation of their acetylene groups may be the origin of such different reactivities. ${ }^{21}$ On the other hand, both the Co and Ta catalysts initiated the polycyclotrimerization of 3 effectively and produced partially and completely insoluble homopolymers in almost quantitative yields. The lack of flexible aliphatic spacers in the monomer and the intermolecular crosslinking between the unterminated acetylene groups may be the causes of the insolubility. Attempts including shortening the reaction time and lowering the diyne concentration were not successful, giving oligomeric products that were difficult to precipitate in the poor solvent.

Another way to gain control over the growth of polycyclotrimerization is through copolymerization of diynes with monoynes. The monoynes here play a twofold role. First, they may function as scavengers or propagation controlling agents, terminating the peripheral reactive triple bonds of the polymers and consequently suppressing the crosslinking reaction. Second, the monoynes may incorporate additional functionality into the hyperbranched polymers or may impart better solubility through attached aliphatic chains to the polymers. Our concept 
worked very well: the copolymerizations between the diynes (1-3) and the monoynes, 1octyne (4) and phenylacetylene (5), in different ratios proceeded smoothly and soluble, high molecular weight copolymers were obtained in high yields (Table 2). As expected, the amount of monoyne necessary for controlling the polymer growth is highly dependant on the type of monomers. Whereas a diyne to monoyne ratio of $1: 1$ is sufficient for $\mathrm{P2} / \mathbf{5}$ and $\mathrm{P3} / \mathbf{4}$, an increased ratio of 1:2 is needed to render the copolyarylenes $\mathrm{P} \mathbf{1} / \mathbf{4}, \mathrm{P} \mathbf{1} / \mathbf{5}$, and P3/5 soluble. The scavenger functionality of the monoynes becomes very clear when we look at P3/4. A diyne to monoyne ratio of 1:1 results in the formation of a high molecular weight polymer, however, with an extremely broad polydispersity (Table 2, entry 11). Increasing the monoyne fraction in the feed mixture to 1.5 times that of the diyne concentration lowers expectedly the molecular weight, but at the same time gives better control over the polymer growth as it significantly narrows the molecular weight distribution (Table 2 , entry 12 ).

\section{Structural Characterization}

All the polymers were characterized by IR, ${ }^{1} \mathrm{H}$ and ${ }^{13} \mathrm{C}$ NMR spectroscopies, which gave analytic data satisfactorily corresponding to their expected molecular structures (see Experimental section for details). Figure 1 depicts an example of the IR spectra of diyne 2 and its copolymer $\mathrm{P2} / \mathbf{5}$. The IR bands associated with the stretching vibrations of $\equiv \mathrm{C}-\mathrm{H}$ and $\mathrm{C} \equiv \mathrm{C}$ of $\mathbf{2}$ are

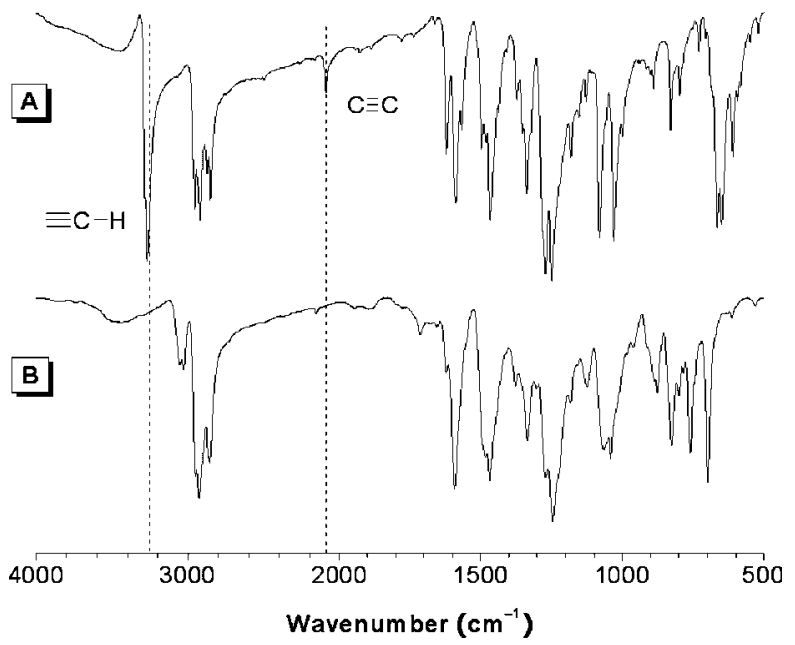

Figure 1. IR spectra of (A) diyne 2 and (B) its copolymer P2/5 (sample taken from Table 2, no. 9).

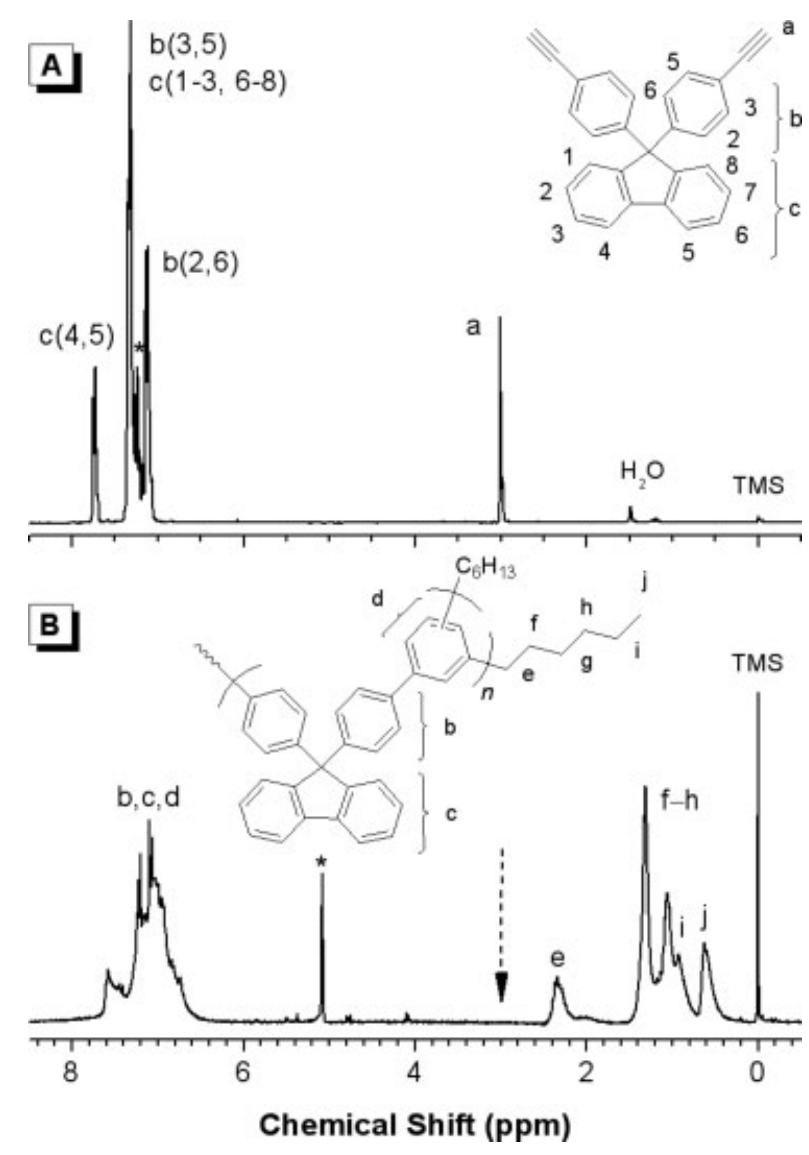

Figure 2. ${ }^{1} \mathrm{H}$ NMR spectra of (A) monomer 3 in chloroform- $d$ and (B) its copolymer P3/4 in DCM- $d_{2}$ (sample taken from Table 2, no. 12). The solvent peaks are marked with asterisks.

observed at 3270 and $2092 \mathrm{~cm}^{-1}$, respectively, which are completely absent in the spectrum of its copolymer after the polycyclotrimerization. Instead, the absorption peaks associated with the aromatic $=\mathrm{C}-\mathrm{H}$ and $\mathrm{C}=\mathrm{C}$ stretchings at 3100 and $1600 \mathrm{~cm}^{-1}$ are clearly intensified, due to the transformation of the acetylenic triple bonds of the monomers to the newly formed benzene rings of the polymer. The analysis of the fingerprint area reveals similar results. The resonance peak at $825 \mathrm{~cm}^{-1}$, associated with the absorption of two neighboring aromatic protons due to newly formed 1,2,4-trisubsitituted benzene rings ${ }^{24}$ becomes clearly stronger. Additionally, the more intense peaks at 760 and 698 $\mathrm{cm}^{-1}$ indicate the successful incorporation of phenylacetylene as comonomer.

Figure 2 shows the ${ }^{1} \mathrm{H}$ NMR spectra of P3/4 and its monomer 3 . The resonance peak at $\delta$ $\sim 3.01$ (a) assigned to the acetylenic proton absorption of $\mathbf{3}$ completely disappears in the 
spectrum of its copolymer P3/4, suggesting that all the triple bonds have been converted to benzene rings by the polymerization reaction. Additionally, the resonance peaks in the aromatic region of $\delta$ 8-6.5 become broader and intensified, suggesting that the $h b$-PAs possess irregular and rigid structures. The resonances of the aliphatic protons from 1-octyne unit are observed in the upfield regions of the spectrum. While the propargyl protons of $\mathbf{4}$ are transformed into the benzyl protons (e) and now resonate at $\delta \sim 2.35$, the remaining resonances $(\mathrm{f}-\mathrm{j})$ are found at $\delta 2-0.5$. All the resonance peaks can readily be assigned with no unexpected signals found, confirming that the product is indeed P3/4, as shown in Scheme 1.

To gain more insights into the structures of the copolymers, the areas of the proton resonance peaks were integrated and analyzed. We first tried to estimate the composition of the diyne (II) and monoyne (I) units inside the $h b$ PAs $\left(N_{\mathrm{II}} / N_{\mathrm{I}}\right)$. For the copolymers prepared from 1-octyne and the diynes $\mathbf{1}$ and $\mathbf{2}$, the methylene peaks of the newly formed benzyl unit at $\delta$ $\sim 2.5$ are compared with the $-\mathrm{OCH}_{2}$ peaks located at $\delta \sim 4.0$, originated from the hexyloxy group. The $N_{\text {II }} / N_{\text {I }}$ ratios for $\mathrm{P} \mathbf{1} / \mathbf{4}$ and $\mathrm{P} 2 / \mathbf{4}$ are found to be $0.81(1 / 1.24)$ and 0.88 (1/1.14), respectively. Since diyne 3 does not possess such separate peaks, the molar composition of its copolyarylenes has to be calculated in a different way. Inspecting the ${ }^{1} \mathrm{H}$ NMR spectra of $\mathrm{P3} / \mathbf{4}$ reveals that the methylene resonance of the benzyl unit at $\delta \sim 2.35$ [peak e in Fig. 2(B)] is clearly free from the interference by other peaks. Using the integrated areas of the resonance peaks of the aromatic and methylenic protons, the ratios of the numbers of diyne and monoyne units can be estimated according to eq 1 :

$$
\frac{N_{\mathrm{II}}}{N_{\mathrm{I}}}=\frac{\left(A_{\mathrm{Ph}}-A_{\mathrm{Ph}-\mathrm{CH}_{2}} / 2\right) / n_{\mathrm{H}, \mathrm{II}}}{A_{\mathrm{Ph}-\mathrm{CH}_{2}} / 2}=\frac{2 A_{\mathrm{Ph}}-A_{\mathrm{Ph}-\mathrm{CH}_{2}}}{n_{\mathrm{H}, \mathrm{II}} A_{\mathrm{Ph}-\mathrm{CH}_{2}}}
$$

where $n_{\mathrm{H}, \mathrm{II}}$ is the total number of acetylenic and aromatic protons in the diyne and $A_{\mathrm{Ph}}$ and $A_{\mathrm{Ph}-\mathrm{CH}_{2}}$ are the integrated areas of the resonance peaks of the phenyl $(\mathrm{Ph})$ and benzyl methylene $\left(\mathrm{Ph}-\mathrm{CH}_{2}\right)$ protons in the copolymers, respectively. For P3/4, an $N_{\mathrm{II}} / N_{\mathrm{I}}$ ratio of 1.0 (1:1) was calculated.

The molar ratio between diynes $\mathbf{1}$ and $\mathbf{2}$ and their comonomer phenylacetylene (5) can be estimated by comparing the integrated areas of the
$-\mathrm{OCH}_{2}$ group with the total areas of the aromatic resonance peaks, which can be expressed by eq 2 :

$$
\begin{aligned}
\frac{N_{\mathrm{II}}}{N_{\mathrm{I}}} & =\frac{A_{\mathrm{II}, \mathrm{OCH}} / n_{\mathrm{II}, \mathrm{OCH}}}{\left[A_{\mathrm{Ph}}-\left(n_{\mathrm{H}, \mathrm{II}} A_{\mathrm{II}, \mathrm{OCH}_{2}} / n_{\mathrm{II}, \mathrm{OCH}_{2}}\right)\right] / n_{\mathrm{H}, \mathrm{I}}} \\
& =\frac{n_{\mathrm{H}, \mathrm{I}} A_{\mathrm{II}, \mathrm{OCH}}}{n_{\mathrm{II}, \mathrm{OCH}_{2}} A_{\mathrm{Ph}}-n_{\mathrm{H}, \mathrm{II}} A_{\mathrm{II}, \mathrm{OCH}_{2}}}
\end{aligned}
$$

where $n_{\mathrm{I}, \mathrm{Ph}}$ is the number of acetylenic and aromatic protons in the monoyne and $n_{\mathrm{II}, \mathrm{OCH}_{2}}$ and $A_{\mathrm{II}, \mathrm{OCH}_{2}}$ are the number and integrated area of the resonance peaks of the methyleneoxy protons in the diynes and copolymers, respectively. Copolyarylenes P1/5 and P2/5 were found to have $N_{\mathrm{II}} / N_{\mathrm{I}}$ ratios of 0.65 and 0.8 , respectively. Unfortunately, diyne 3 and monoyne 5 possess no protons in the non-aromatic region and it is therefore much more difficult to calculate the molar ratio of the two monomers. It is, however, anticipated that P3/5 has a molar ratio comparable to that of its congeners P1/5 and P2/5.

The number of the diyne and monoyne units in the copolymer is furthermore related by eq 3 :

$$
N_{\mathrm{I}}=N_{\mathrm{II}}+3-3 m
$$

where $m$ is the number of cyclic structures in the hyperbranched polymer. Assuming that no cyclic structures have been formed via internal cyclizations and backbiting propagations, the number of diyne units can be estimated according to eq 4 :

$$
N_{\mathrm{I}}=N_{\mathrm{II}}+3
$$

Combining eqs 1 and 2 with eq 4 gives access to $N_{\text {II }}$ and $N_{\text {I }}$, which allows calculations of number-average molecular weights of the copolymers from their NMR spectral data by eq 5 :

$$
M_{\mathrm{n}, \mathrm{c}}=N_{\mathrm{II}} M_{\mathrm{II}, 0}+N_{\mathrm{I}} M_{\mathrm{I}, 0}
$$

where $M_{\mathrm{n}, \mathrm{c}}$ is the calculated number-average molecular weight and $M_{\mathrm{II}, 0}$ and $M_{\mathrm{I}, 0}$ are the molecular weights of the diyne and monoyne monomers, respectively. Copolymers $\mathrm{P} 1 / \mathbf{4}$ and $\mathrm{P2} / \mathbf{4}$ with their $N_{\mathrm{II}} / N_{\mathrm{I}}$ ratio of 0.81 and 0.88 relate to calculated molecular weights $\left(M_{\mathrm{n}, \mathrm{c}}\right)$ of 6000 and 8820 , respectively, and $M_{\mathrm{n}, \mathrm{c}}$ values of 2870 and 4840 has been determined for the copolymers of $\mathbf{1}$ and $\mathbf{2}$ with phenylacetylene (5), respectively (Table 3 ).

The calculated molecular weights are in good agreement with the experimental values estimated from GPC. The small differences may be 
Table 3. Molecular Weights of Hyperbranched Polyarylenes Calculated from NMR Data and Estimated by GPC Analysis

\begin{tabular}{llllrrrc}
\hline No. & $h b-\mathrm{PA}$ & $n_{\mathrm{II}} / n_{\mathrm{I}}{ }^{\mathrm{a}}$ & $N_{\mathrm{II}} / N_{\mathrm{I}}{ }^{\mathrm{b}}$ & $N_{\mathrm{II}}$ & $N_{\mathrm{I}}$ & $M_{\mathrm{n}, \mathrm{c}}{ }^{\mathrm{c}}$ & $M_{\mathrm{n}}{ }^{\mathrm{d}}$ \\
\hline 1 & $\mathrm{P} \mathbf{1} / \mathbf{4}$ & 0.5 & 0.81 & 13 & 16 & 6000 & 6770 \\
2 & $\mathrm{P} \mathbf{5} / 5$ & 0.5 & 0.65 & 6 & 9 & 2870 & 2800 \\
3 & $\mathrm{P} 2 / \mathbf{4}$ & 0.67 & 0.88 & 22 & 25 & 8820 & $\mathrm{e}$ \\
4 & $\mathrm{P} 2 / 5$ & 1.0 & 0.80 & 12 & 15 & 4840 & 3390 \\
5 & $\mathrm{P} 3 / 4$ & 0.67 & 1.0 & $12^{\mathrm{f}}$ & $12^{\mathrm{f}}$ & $5710^{\mathrm{f}}$ & 5620 \\
\hline
\end{tabular}

${ }^{\text {a }}$ Molar ratio of the number of diyne units $\left(n_{\mathrm{II}}\right)$ to the number of monoyne units $\left(n_{\mathrm{I}}\right)$ in the comonomer feed mixture.

${ }^{\mathrm{b}}$ Molar ratio of the number of diyne units $\left(N_{\mathrm{II}}\right)$ to the number of monoyne units $\left(N_{\mathrm{I}}\right)$ in the copolymer as determined from ${ }^{1} \mathrm{H}$ NMR spectral data.

${ }^{\mathrm{c}}$ Calculated from the integrated area of the resonance peaks in the ${ }^{1} \mathrm{H}$ NMR spectra.

${ }^{d}$ Measured in THF on the basis of a polystyrene calibration.

${ }^{\mathrm{e}}$ Sample was only partially soluble in THF and an accurate molecular weight determination was not possible.

${ }^{\mathrm{f}}$ Calculation based on the $M_{\mathrm{n}}$ value determined from GPC.

caused by internal cyclization reactions, which lower the monoyne content and thus increase the $N_{\mathrm{II}} / N_{\mathrm{I}}$ ratio. Another reason for the generally lower experimental values may be the fact that the polystyrene-calibrated GPC analysis has underestimated the molecular weights of the hyperbranched polymers due to their generally more globular sizes. ${ }^{25,26}$ The later explanation seems predominate in our case, although the first one cannot be completely excluded. This becomes immediately clear when we look at the $N_{\mathrm{II}} / N_{\mathrm{I}}$ ratio of $\mathrm{P} \mathbf{3} \mathbf{4}$. The comonomer ratio for P3/4 has been determined to be 1.0, which suggests either a very high molecular weight (cf. eq $4, N_{\text {II }} \approx N_{\mathrm{I}}$ ) or the formation of at least one internal cyclization reaction per macromolecule (cf. eq 3). Unfortunately, upon the formation of an internal cycle, the molecular weight of the hyperbranched polymer is no longer dependant on the comonomer ratio and consequently cannot be estimated from its NMR spectral data. Assuming that the experimentally determined $M_{\mathrm{n}}$ value of 5620 is true, P3/4 would consist in the average of about 12 monoyne and diyne units together with one internal cycle.

Comparison of the $n_{\mathrm{II}} / n_{\mathrm{I}}$ ratios in the comonomer mixtures with the $N_{\text {II }} / N_{\text {I }}$ ratios in the copolymers reveals that in general the amount of diyne units incorporated into the copolymer structure is increased. This is expected and can be easily understood. Considering the fact that in most copolymerization reactions the monoynes are present in excess and consequently the $[2+2+2]$ cyclotrimerization of $\mathbf{4}$ or $\mathbf{5}$ forms trisubstituted benzenes, without the ability to propagate further and hence will not contribute to the polymer growth.

To verify the proposed polycyclotrimerization mechanism and to get more insights into the structures of the polymers, we further characterized them by ${ }^{13} \mathrm{C}$ NMR spectroscopy. Figure 3 shows an example of the ${ }^{13} \mathrm{C}$ NMR spectrum of P3/5 along with that of its diyne monomer (3). The acetylenic carbons of $\mathbf{3}$ resonate at $\delta 83.4$ and 77.4, which are absent in the spectrum of P3/5. Many peaks are observed in the spectral region of aromatic carbons. These peaks are the sum of the resonances of the aromatic carbons of the fluorenyl and phenyl moieties from the monomers as well as the new phenyl rings formed by the alkyne polycyclotrimerization. All the above spectroscopic data suggest that the

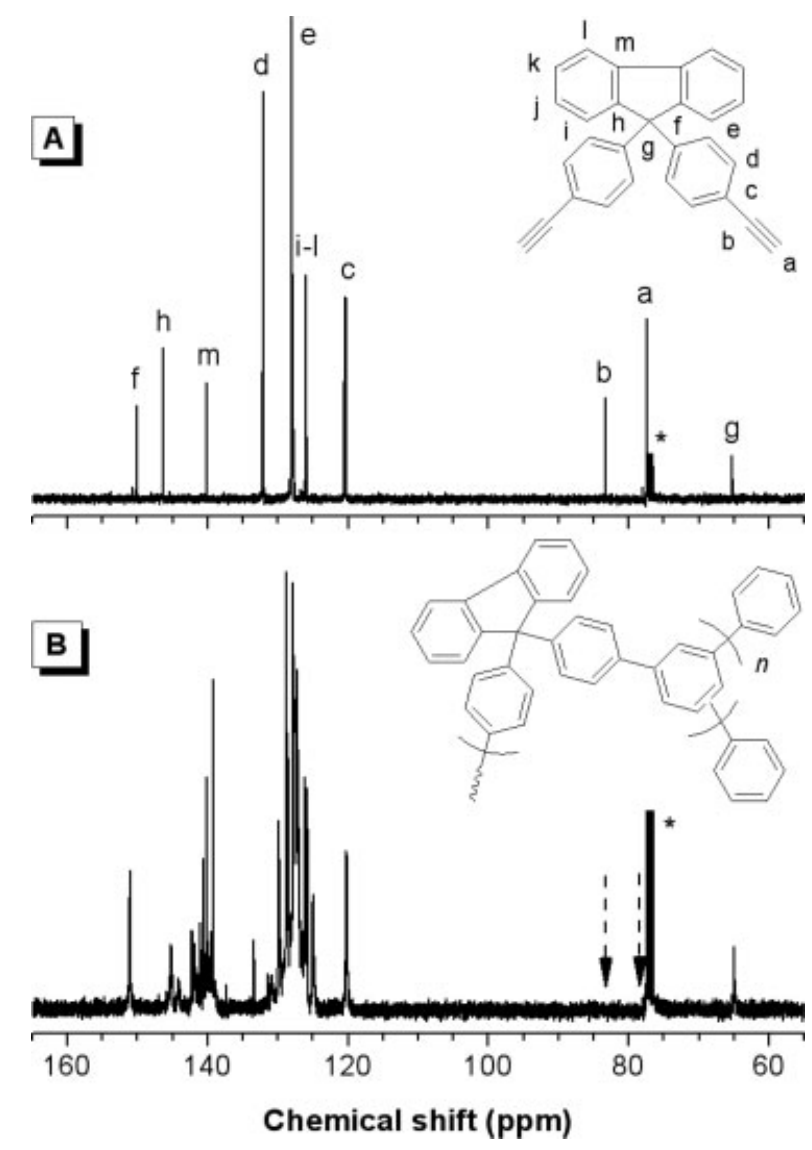

Figure 3. ${ }^{13} \mathrm{C}$ NMR spectra of (A) monomer 3 and (B) its copolymer P3/5 (sample taken from Table 2, no. 14) in chloroform- $d$. The solvent peaks are marked with asterisks.

Journal of Polymer Science: Part A: Polymer Chemistry 
diyne monomers have been polymerized by the transition-metal catalysts via the $[2+2+2]$ polycycloaddition mechanism.

An important structural parameter for hyperbranched polymers is the degree of branching (DB), which is defined as:

$$
\mathrm{DB}=(\mathrm{D}+\mathrm{T}) /(\mathrm{D}+\mathrm{L}+\mathrm{T})
$$

or according to Frey ${ }^{27}$ for high molecular weight polymers $(\mathrm{D}=\mathrm{T})$ :

$$
\mathrm{DB}=2 \mathrm{D} /(2 \mathrm{D}+\mathrm{L})
$$

where $\mathrm{D}, \mathrm{L}$, and $\mathrm{T}$ are the dendritic, linear, and terminal units, respectively. By definition, a completely linear polymer has a DB of 0 , and the DB becomes unity for a perfectly branched dendrimer. The above determination of the composition $\left(N_{\mathrm{II}} / N_{\mathrm{I}}\right)$ of the $h b$-PAs, however, does not give any information about their internal structure as the molar ratio is independent of DB. Model reactions of homo- and cocyclotrimerizations of monoynes 4 and 5 reveal the formation of 1,3,5- and 1,2,4-trisubstitued benzene rings. ${ }^{21}$ The presence of these two isomeric structures translates into a total of 10 possible structural units inside the hyperbranched architecture (Chart 1). Aggravatingly, the resonance peaks of the "new" benzene rings of the $h b$-PA in the ${ }^{1} \mathrm{H}$ and ${ }^{13} \mathrm{C}$ NMR spectra overlap with the "old" aromatic moieties, which makes it difficult, if not impossible, to distinguish between the structural features even when high resolution NMR techniques were employed.

Instead of obtaining the DB from the polymers directly, we previously conducted the model reactions of the monoynes, phenylacetylene and 1-octyne, under the conditions identical to those used in the polymerization reactions. The resultant small "fragments" should be identical to the building blocks of the polymers and

\section{Dendritic unit $(D)$}

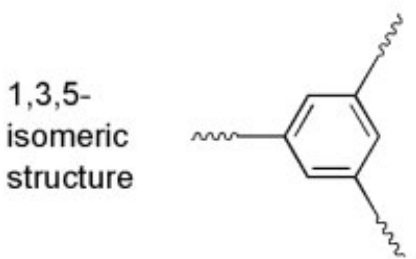

$1,2,4-$

isomeric

structure

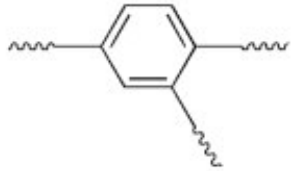

$\sim m s=$ polymer $\quad \mathrm{R}=\mathrm{C}_{6} \mathrm{H}_{13}$

branch $\quad \mathrm{C}_{6} \mathrm{H}_{5}$
Linear unit $(L)$
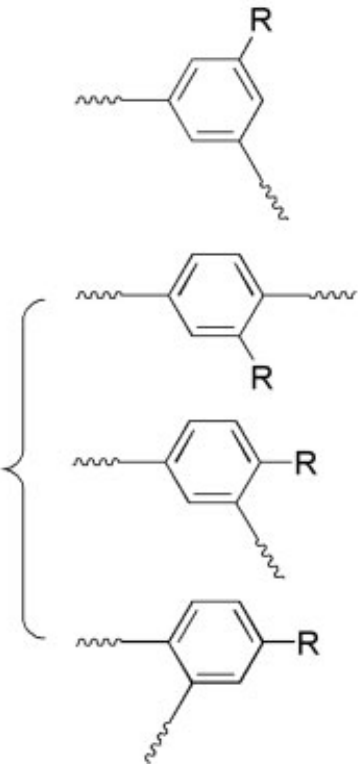

Terminal unit $(T)$
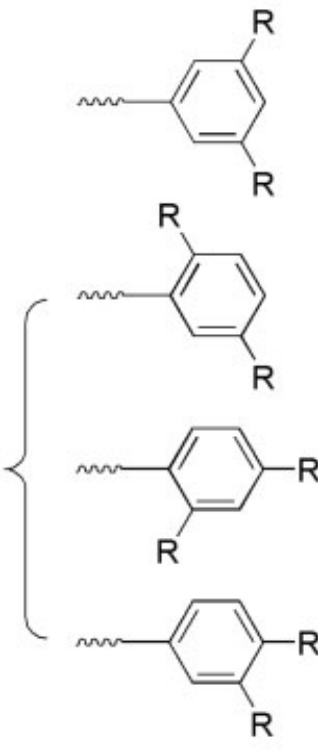

Definition of the $D, L$ and $T$ substructure

units in the "classical" hyperbranched

polymers synthesized from

$\mathrm{AB}_{2}$ monomers

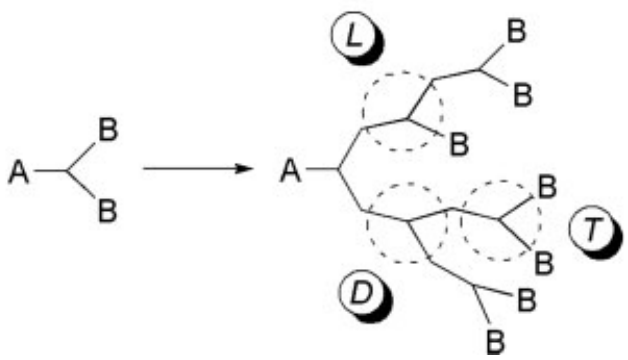

Chart 1. Structures of dendritic (D), linear (L), and terminal (T) units in $h b$-PAs. 


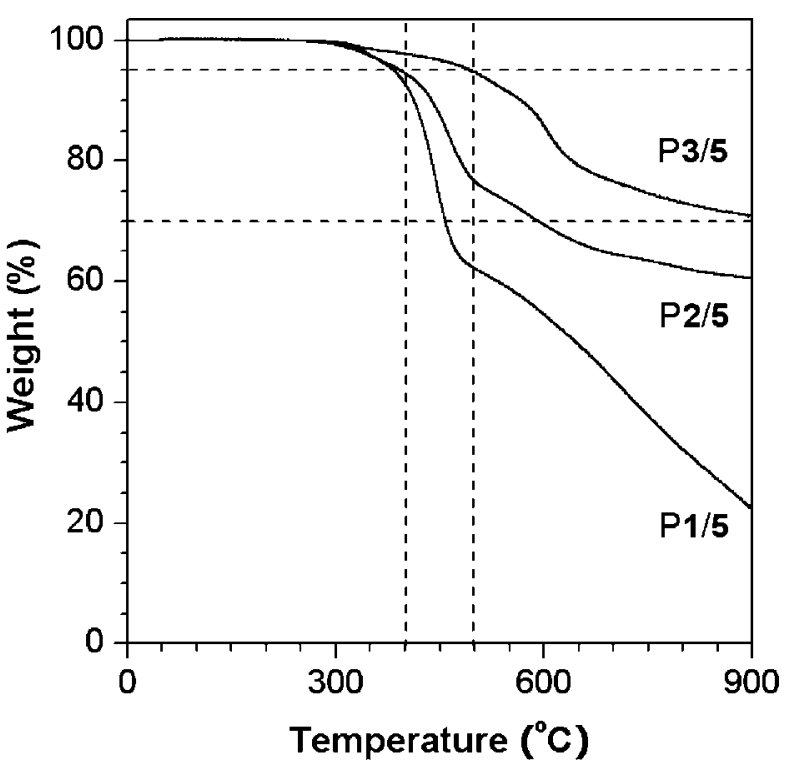

Figure 4. TGA thermograms of P1/5, P2/5, and P3/ 5 recorded under nitrogen at a heating rate of $20{ }^{\circ} \mathrm{C} /$ min. Samples were taken from Table 2, nos. 6, 9, and 14 , respectively.

could then be analyzed by high-resolution NMR. $\mathrm{DB}$ values $0.05-0.11$, depending on the ratios of comonomers used, have been determined. ${ }^{21(f)}$ The polymerization conditions used in this work are comparable and it is thus reasonable to believe that the $h b$-PAs prepared here are similarly moderately branched. Although the DB values appear to be on the lower side of the spectrum, the presence of dendritic units in the polyarylenes qualifies them as hyperbranched polymers.

Table 4. Thermal and Optical Properties of Hyperbranched Polyarylenes

\begin{tabular}{llccccc}
\hline No. & $h b-\mathrm{PA}$ & $T_{\mathrm{d}}{ }^{\mathrm{a}}\left({ }^{\circ} \mathrm{C}\right)$ & $W_{\mathrm{r}}^{\mathrm{b}}(\mathrm{wt} \%)$ & $\lambda_{\mathrm{ab}}{ }^{\mathrm{c}}$ & $\lambda_{\mathrm{em}}{ }^{\mathrm{c}}$ & $\Phi_{\mathrm{F}}{ }^{\mathrm{d}}(\%)$ \\
\hline 1 & $\mathrm{P} 1 / 4$ & 360 & 18 & 352 & 400 & 87 \\
2 & $\mathrm{P} \mathbf{5} / \mathbf{5}$ & 385 & 22 & 355 & 402 & 92 \\
3 & $\mathrm{P} 2$ & 390 & 40 & 345 & 397 & 2 \\
4 & $\mathrm{P} 2 / \mathbf{5}$ & 393 & 60 & 361 & 397 & 11 \\
5 & $\mathrm{P3} / \mathbf{4}$ & 476 & 60 & 295 & 362 & 2 \\
6 & $\mathrm{P} 3 / \mathbf{5}$ & 493 & 71 & 296 & 368 & 1 \\
\hline
\end{tabular}

\footnotetext{
a Temperature for $5 \%$ weight loss.

${ }^{\mathrm{b}}$ Weight of the residue left at $900{ }^{\circ} \mathrm{C}$.

${ }^{\mathrm{c}}$ Maximum absorption (ab) and emission (em) wavelengths measured in dichloromethane.

${ }^{\mathrm{a}}$ Determined using 9,10-diphenylanthracene in cyclohexane $\left(\Phi_{\mathrm{F}}=90 \%\right)$ as standard.
}

\section{Thermal and Optical Properties}

The thermal properties of the $h b$-PAs were investigated by TGA under nitrogen. Thanks to their aromatic skeleton architecture, most of the polymers show excellent thermal stability, with degradation temperatures $\left(T_{\mathrm{d}}\right)$ as high as $\sim 400{ }^{\circ} \mathrm{C}$ (Fig. 4). Among the polymers, P3/5 is outstandingly stable. The copolymer prepared from the fluorenyl diyne and phenylacetylene loses merely $5 \%$ of its weight when heated up to $\sim 500{ }^{\circ} \mathrm{C}$ and graphitizes in a yield as high as $71 \%$ (Table 4). Comparing the $T_{\mathrm{d}}$ values of the $h b$-PAs, the thermal stability is in the order of $\mathrm{P} 3 / \mathbf{5}>\mathrm{P} 2 / 5>\mathrm{P} \mathbf{1} / \mathbf{5}$. This is understandable because the hexyloxy groups on the phenyl and naphthyl rings in P1/5 and $\mathrm{P} 2 / 5$ are easily ripped off upon thermolysis. The same is true when the $h b$-PAs are prepared from the same diynes but different monoynes. For example, P1/ 5, a copolymer constructed from 1 and aromatic phenylacetylene, starts to decompose at $385{ }^{\circ} \mathrm{C}$, whereas its congener P1/4, using aliphatic 1octyne as terminating agent, shows already a $5 \%$ weight loss at $360{ }^{\circ} \mathrm{C}$. The TGA results are fully consistent with our previous results and verify the polyaromatic nature of our polymers. ${ }^{21}$

Conjugated polyarylenes are organic semiconductors and their optical and electronic prop-

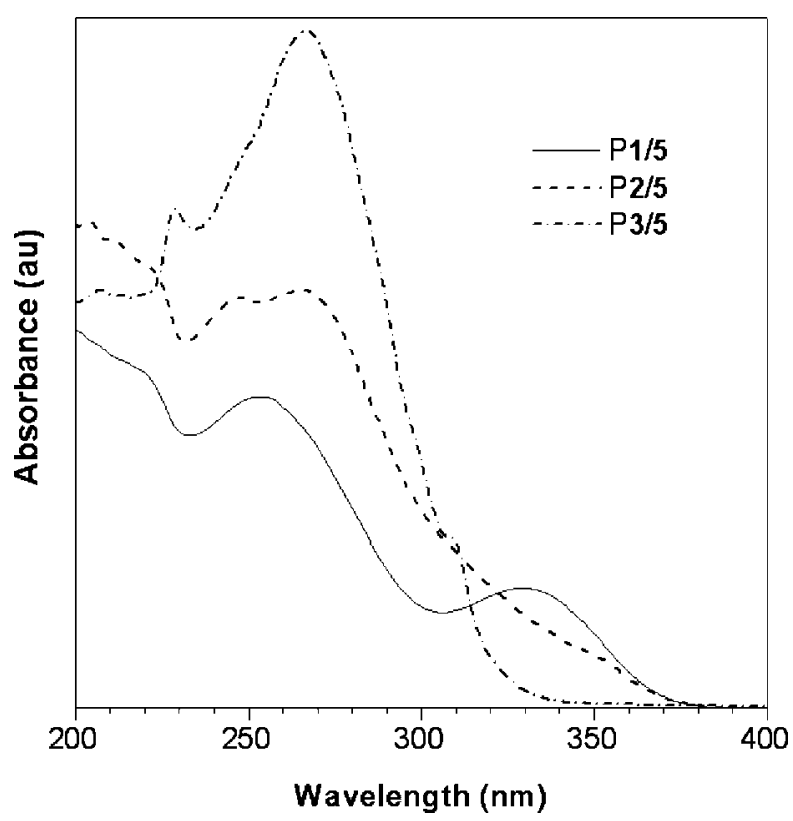

Figure 5. UV spectra of DCM solutions of P1/5, P2/ 5, and P3/5 $(0.012 \mathrm{mg} / \mathrm{mL})$. Samples were taken from Table 2, nos. 6, 9, and 14, respectively.

Journal of Polymer Science: Part A: Polymer Chemistry 


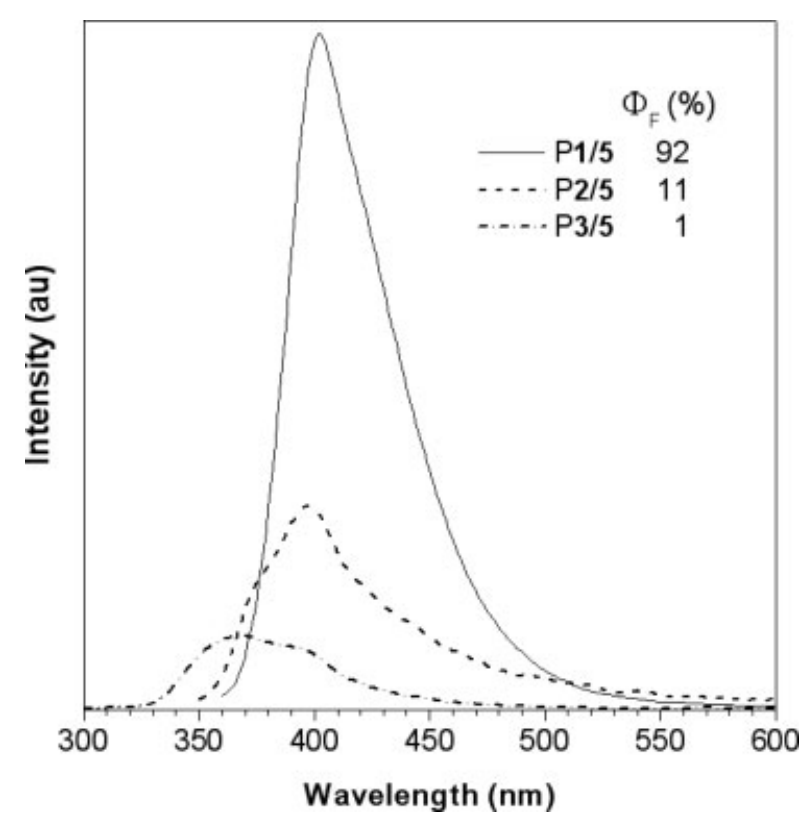

Figure 6. Fluorescence spectra of DCM solutions of P1/5, P2/5, and P3/5. Concentration: $0.012 \mathrm{mg} / \mathrm{mL}$. Excitation wavelength (nm): 355 (P1/5), 345 (P2/5), 296 (P3/5). Samples were taken from Table 2, nos. 6, 9 , and 14 , respectively.

erties strongly depend on their molecular backbone architectures. ${ }^{28}$ Linear, rigid rod-like macromolecules often experience strong $\pi-\pi$ interactions and suffer from excimer formation. It has been demonstrated that introduction of branches to the polymer structure helps overcome these obstacles. ${ }^{29}$ We studied the optical properties of the $h b$-PAs by absorption and fluorescence spectroscopies. The polymers exhibit strong peaks associated with the absorptions of their conjugated chromophores (Fig. 5). Whereas the absorption maximum for P1/5 is at $250 \mathrm{~nm}$, those of P2/5 and P3/5 are bathochromically shifted to 265 and $267 \mathrm{~nm}$, respectively, due to their more polarized chromophoric cores. It is noteworthy that the absorption edges of P1/5 and $\mathrm{P} 2 / 5$ are at $\sim 380 \mathrm{~nm}$, much longer than that of P3/5 $(\sim 340 \mathrm{~nm})$. The $\mathrm{sp}^{3}$ carbon at the 9 position of fluorene ring may have shut off the electronic communications in the P3/5 system, thus blue-shifts its absorption edge.

DCM solutions of the $h b$-PAs emit UV to deep blue lights when photoexcited. Examples of their fluorescence spectra are given in Figure 6. Polymer P1/5 emits a strong, deep blue light of $405 \mathrm{~nm}$ with a fluorescence quantum yield $\left(\Phi_{\mathrm{F}}\right)$ as high as $92 \%$. Its structural congener, $\mathrm{P} \mathbf{1} / \mathbf{4}$, is a similarly strong emitter with a $\Phi_{\mathrm{F}}$ of $87 \%$
(Table 4). The small difference might be caused by the choice of comonomer, as phenylacetylene may contribute additional conjugation to the branched polyarylene structure. As a result, its maximum absorption and emission wavelengths are both bathochromically shifted. Less efficient emissions (11 and 1\%, respectively) are observed in P2/5 and P3/5. The new benzene rings formed by polycyclotrimerization in P3/5 are connected through the phenyl groups at the 9 position of the fluorene ring. The conjugation is thus poorer when compared to its 2,7-substituted congeners, thus leading to the lower emission efficiency in P3/5.

Table 4 summarizes the thermal and optical properties of the $h b$-PAs. The polymers show excellent thermal stability with residues up to 71 wt $\%$ when pyrolyzed to $900{ }^{\circ} \mathrm{C}$ under nitrogen, making them promising precursors to carbon-rich materials. The light emission efficiency of the $h b$-PA is sensitive to its molecular structure, offering a nice opportunity to tune its optical properties through molecular engineering endeavor.

\section{CONCLUSIONS}

New $h b$-PAs have been synthesized by a singlestep, one-pot polycyclotrimerization of alkynes using $\mathrm{CpCo}(\mathrm{CO})_{2}-h v$ or $\mathrm{TaBr}_{5}-\mathrm{Ph}_{4} \mathrm{Sn}$ as catalyst. Detailed NMR analyses reveal the compositions of the polymers and confirm their hyperbranched structures. The polymers show high thermal stability and emit UV to deep blue lights upon photoexcitation.

This project was partially supported by the Research Grants Council of Hong Kong (602706, HKU2/05C, 603505, and 603304), the National Science Foundation of China (20634020), and the Ministry of Science and Technology of China (2002CB613401). B. Z. Tang thanks the support of the Cao Guangbiao Foundation of Zhejiang University.

\section{REFERENCES AND NOTES}

1. Frechet, J. M. J.; Tomalia, D. A. Dendrimers and Other Dendritic Polymers; Wiley: Chichester, 2001.

2. Newkome, G. R.; Vogtle, F.; Moorefield, C. N. Dendrimers and Dendrons; Wiley: Weinheim, 2001. 
3. (a) Van Heerbeek, R.; Kamer, P. C. J.; Van Leeuwen, P. W. N. M.; Reek, J. N. H. Chem Rev 2002, 102, 3717; (b) Astruc, D.; Chardac, F. Chem Rev 2001, 101, 2991.

4. Twyman, L. J.; King, A. S. H.; Martin, I. K. Chem Soc Rev 2002, 31, 69.

5. Nehls, B. S.; Galbrecht, F.; Brauer, D. J.; Lehmann, C. W.; Scherf, U.; Farrell, T. J Polym Sci Part A: Polym Chem 2006, 44, 5533.

6. Frechet, J. M. J. J Polym Sci Part A: Polym Chem 2003, 41, 3713

7. Newkome, G. R.; He, E.; Moorefield, C. N. Chem Rev 1999, 99, 1689.

8. Cuadrado, I.; Morán, M.; Casado, C. M.; Alonso, B.; Losada, J. Coord Chem Rev 1999, 193, 395.

9. (a) Kim, Y. H. J Polym Sci Part A: Polym Chem 1998, 36, 1685; (b) Voit, B. J Polym Sci Part A: Polym Chem 2000, 38, 2505; (c) Himmelberg, P.; Fossum, E. J Polym Sci Part A: Polym Chem 2005, 43, 3178.

10. (a) Jikei, M.; Kakimoto, M.-A. Prog Polym Sci 2001, 26, 1233; (b) Voit, B. J Polym Sci Part A: Polym Chem 2005, 43, 2679.

11. (a) Inoue, K. Prog Polym Sci 2000, 25, 453; (b) Kubisa, P. J Polym Sci Part A: Polym Chem 2003, 41, 457; (c) Hecht, S. J Polym Sci Part A: Polym Chem 2003, 41, 1047; (d) Guan, Z. J Polym Sci Part A: Polym Chem 2003, 41, 3680; (e) Froehling, P. J Polym Sci Part A: Polym Chem 2004, 42, 3110.

12. Schluter, A. D.; Wegner, G. Acta Polym 1993, 44, 59.

13. Watson, M. D.; Fechtenkotter, A.; Mullen, K. Chem Rev 2001, 101, 1267.

14. (a) Gao, C.; Yan, D. Prog Polym Sci 2004, 29, 183; (b) Monticelli, O.; Mariani, A.; Voit, B.; Bomber, H.; Mendichi, R.; Pitto, V.; Tabuani, D.; Russo, S. High Perform Polym 2001, 13, 45; (c) Davis, N.; Rannard, S. J Am Chem Soc 2000, 122, 11729; (d) Jikei, M.; Kakimoto, M.-A. J Polym Sci Part A: Polym Chem 2004, 42, 1293; (e) van Benthem, R. A. T. M.; Meijerink, N.; Gelade, E.; de Koster, C. G.; Muscat, D.; Froehling, P. E.; Hendriks, P. H. M.; Vermeulen, C. J. A. A.; Zwartkuis, T. J. G. Macromolecules 2001, 34, 3559.

15. (a) Simon, P. F. W.; Radke, W.; Müller, A. H. E. Macromol Rapid Commun 1997, 18, 865; (b) Sakamoto, K.; Aimiya, T.; Kira, M. Chem Lett 1997, 1245; (c) Matyjaszewski, K.; Gaynor, S. G.; Kulfan, A.; Podwika, M. Macromolecules 1997, 30, 5192; (d) Yan, D.; Zhou, Z.; Mueller, A. Macromolecules 1999, 32, 245; (e) Baskaran, D. Polymer 2003, 44, 2213; (f) Cheng, C.; Wooley, K. L.; Khoshdel, E. J Polym Sci Part A: Polym Chem 2005, 43, 4754 .

16. (a) Chang, H.-T.; Frechet, J. M. J. J Am Chem Soc 1999, 121, 2313; (b) Dworak, A.; Walach, W.; Trzebicka, B. Macromol Chem Phys 1995, 196, 1963; (c) Sunder, A.; Hanselmann, R.; Frey, H.;
Mülhaupt, R. Macromolecules 1999, 32, 4240; (d) Suzuki, M.; Yoshida, S.; Shiraga, K.; Saegusa, T. Macromolecules 1998, 31, 1716; (e) Magnusson, H.; Malmström, E.; Hult, A. Macromol Rapid Commun 1999, 20, 453; (f) Bednarek, M.; Biedron, T.; Helinski, J.; Kaluzynski, K.; Kubisa, P.; Penczek, S. Macromol Rapid Commun 1999, 20, 369; (g) Imai, T.; Satoh, T.; Kaga, H.; Kaneko, N.; Kakuchi, T. Macromolecules 2004, 37, 3113.

17. (a) Morgenroth, F.; Müllen, K. Tetrahedron 1997, 53, 15349; (b) Stumpe, K.; Komber, H.; Voit, B. I. Macromol Chem Phys 2006, 207, 1825.

18. (a) Häußler, M.; Tang, B. Z. Adv Polym Sci 2007, 209, 1; (b) Qin, A.; Haeussler, M.; Lam, J. W. Y.; Tse, K. K. C., Tang, B. Z. Polym Prepr 2006, 47, 681; (c) Qin, A.; Jim, C. K. W.; Lu, W.; Lam, J. W. Y.; Häußler, M.; Dong, Y. Q.; Sung, H. H. Y.; Williams, I. D.; Wong, G. K. L.; Tang, B. Z. Macromolecules 2007, 40, 2308.

19. (a) Scheel, A.; Komber, H.; Voit, B. Macromol Rapid Commun 2004, 25, 1175; (b) Li, C.; Finn, M. G. J Polym Sci Part A: Polym Chem 2006, 44, 5513.

20. Dong, H.; Zheng, R.; Lam, J. W. Y.; Häussler, M.; Tang, B. Z. Macromolecules 2005, 38, 6382.

21. (a) Xu, K.; Peng, H.; Sun, Q.; Dong, Y.; Salhi, F.; Luo, J.; Chen, J.; Hunag, Y.; Zhang, D.; Xu, Z.; Tang, B. Z. Macromolecules 2002, 35, 5821; (b) Häußler, M.; Lam, J. W. Y.; Zheng, R.; Peng, H.; Luo, J.; Chen, J.; Law, C. C. W.; Tang, B. Z. C R Chim 2003, 6, 833; (c) Peng, H.; Lam, J. W. Y.; Tang, B. Z. Macromol Rapid Commun 2005, 26, 673; (d) Peng, H.; Cheng, L.; Luo, J.; Xu, K.; Sun, Q.; Dong, Y.; Salhi, F.; Lee, P. P. S.; Chen, J.; Tang, B. Z. Macromolecules 2002, 35, 5349; (e) Zheng, R.; Häussler, M.; Dong, H.; Lam, J. W. Y.; Tang, B. Z. Macromolecules 2006, 39, 7973; (f) Häussler, M.; Liu, J.; Zheng, R.; Lam, J. W. Y.; Qin, A.; Tang, B. Z. Macromolecules 2007, 40, 1914.

22. Zhou, C.-Z.; Liu, T.; Xu, J.-M.; Chen, Z.-K. Macromolecules 2003, 36, 1457.

23. Klapars, A; Buchwald, S. L. J Am Chem Soc 2002, 124, 14844 .

24. (a) Silverstein, R. M.; Webster, F. X.; Kiemle, D. J. Spectrometric Identification of Organic Compounds, 7th ed.; Wiley: Hoboken, 2005; (b) Whittaker, D. Interpreting Organic Spectra; RSC: Cambridge, 2000.

25. Hawker, C. J.; Malmstrom, E. E.; Curtis, W. F. Kampf, J. P. J Am Chem Soc 1997, 119, 9903.

26. Harth, E. M.; Hecht, S.; Helms, B.; Malmstrom, E. E.; Frechet, J. M. J.; Hawker, C. J. J Am Chem Soc 2002, 124, 3926.

27. Holter, D.; Burgath, A.; Frey, H. Acta Polym 1997, 48, 30.

28. (a) Yang, C.; Jacob, J.; Muellen, K. Macromol Chem Phys 2006, 207, 1107; (b) Wang, F.; Wilson, 
M. S.; Rauh, R. D.; Schottland, P.; Thompson, B. C.; Reynolds, J. R. Macromolecules 2000, 33, 2083; (c) Xin, Y.; Wen, G.-A.; Zeng, W.-J.; Zhao, L.; Zhu, X.-R.; Fan, Q.-L.; Feng, J.-C.; Wang, L.-H.; Wei, W.; Peng, B.; Cao, Y.; Huang, W. Macromolecules 2005, 38, 6755; (d) Lim, S.-J.; Seok, D. Y.; An, B.-K.; Jung, S. D.; Park, S. Y. Macromolecules 2006, 39, 9; (e) Yamamoto, T. Macromol Rapid Chem 2002, 23, 583; (f) Goodall, G. W.; Hayes, W. Chem Soc Rev 2006, 35, 280.
29. (a) Law, C. C. W.; Chen, J.; Lam, J. W. Y.; Peng, H.; Tang, B. Z. J Inorg Organomet Polym 2004 , 14, 39; (b) Chen, J.; Peng, H.; Law, C. C. W.; Dong, Y. P.; Lam, J. W. Y.; Williams, I. D.; Tang, B. Z. Macromolecules 2003, 36, 4319; (c) Chen, J.; Kwok, H. S.; Tang, B. Z. J Polym Sci Part A: Polym Chem 2006, 44, 2487; (d) Li, Z.; Li, Q.; Qin, A.; Dong, Y.; Lam, J. W. Y.; Dong, Y.; Ye, C.; Qin, J.; Tang, B. Z. J Polym Sci Part A: Polym Chem 2006, 44, 5672. 